\title{
Does the Atmospheric Global Model MRI-AGCM3.2 Perform Better than CMIP6 Atmospheric Models in Simulating Precipitation?
}

Shoji Kusunoki ( $\square$ skusunok@mri-jma.go.jp )

Meteorological Research Institute (MRI) https://orcid.org/0000-0002-6637-1758

\section{Tosiyuki Nakaegawa}

Meteorological Research Institute (MRI)

Ryo Mizuta

Meteorological Research Institute (MRI)

\section{Research Article}

Keywords: Precipitation, Global atmospheric model, High horizontal resolution model, CMIP6

Posted Date: December 13th, 2021

DOI: https://doi.org/10.21203/rs.3.rs-1139972/v1

License: (1) This work is licensed under a Creative Commons Attribution 4.0 International License.

Read Full License 
1 Does the atmospheric global model MRI-AGCM3.2 perform better than CMIP6 atmospheric models in simulating precipitation?

$6 \quad{ }^{1}$ Department of Climate and Geochemistry Research, Meteorological Research Institute,

7 Tsukuba, Ibaraki, Japan

$8 \quad{ }^{2}$ Faculty of Societal Safety Sciences, Kansai University

$9{ }^{3}$ Department of Applied Meteorology Research, Meteorological Research Institute,

10 Tsukuba, Ibaraki, Japan

11

12 Version dates

134 December 2021 Version 1 Submitted to Climate Dynamics

14

15 Corresponding author Shoji Kusunoki

16 E-mail : skusunoki@mri-jma.go.jp

17 


\section{Abstract}

19 The performance of the Meteorological Research Institute-Atmospheric General

20 Circulation model version 3.2 (MRI-AGCM3.2) in simulating precipitation is compared

21 with that of global atmospheric models registerred to the sixth phase of the Coupled

22 Model Intercomparison Project (CMIP6). The MRI-AGCM3.2 with the grid size of 23 20-km and 60-km and 36 CMIP6 models are forced with observed sea surface 24 temperature for 20-year period from 1995 to 2014 . The horizontal resolution of the MRI-AGCM3.2 is relatively finer than CMIP6 models. As for global domain, the reproducibility of MRI-AGCM3.2 models are better than or equal to CMIP6 models in

27 simulating geographical distribution of annual precipitation and intense precipitation events. Models with higher horizontal resolution tend to be better than those with lower resolution in simulating global precipitation. As for East Asia, the performance of MRI-AGCM3.2 models are better than or equal to CMIP6 models in simulating

31 summertime monthly precipitation and the seasonal march in the Japanese rainy season, and extreme precipitation events. Higher horizontal resolution models also tend to perform better than lower resolution models in simulating precipitation over East Asia.

34 The advantage of models with higher horizontal resolution over those with lower resolution in reproducing precipitation is more evident over East Asia than over the 36 globe. (202 words, Limitation : 150 to 250 words)

39 Keywords Precipitation; Global atmospheric model; High horizontal resolution model; CMIP6 


\section{Introduction}

The performance to simulate current-day climatology by Atmospheric General

44 Circulation Models (AGCMs) is usually assessed by specifying the observed sea surface

45 temperature (SST) as a underlying boundary condition. This sort of simulation is called

46 an Atmosphere Model Intercomparison (AMIP)-type experiment. Lau et al. (1996),

47 Lau and Yang (1996), Liang et al. (2001), Kusunoki et al. (2001) and Kusunoki (2018a)

48 analyzed AMIP-type experiments by AGCMs and reported that simulated precipitation

49 in summer is smaller than observations over East Asia based on AMIP-type experiments.

50 Also, Kang et al. (2002) and Kusunoki 2018a) indicated that most AGCMs do not

51 reproduce the northward marching of summertime rainy band over East Asia.

However, Kusunoki et al. (2006), Kitoh and Kusunoki (2008) and Kusunoki 2018a) revealed that AGCMs with higher horizontal resolution perform better than those with lower horizontal resolution with respect to summer precipitation over East Asia. In the case of simulating heavy rainfall events, Kusunoki et al. (2006) and Randall et al. (2007) indicated the advantage of AGCMs with higher horizontal resolution over those with lower horizontal resolution.

We have been developing a high horizontal resolution global atmospheric model called the Meteorological Research Institute - Atmospheric General Circulation Model

60 (MRI-AGCM) since year 2002. In view of the advantages of higher horizontal

61 resolution models over lower ones in simulating precipitation over East Asia, a series of 62 global warming projections such as Kusunoki et al. (2006, 2011), Kusunoki and Mizuta (2008, 2012, 2013), Endo et al. (2012), Okada et al. (2017), Kusunoki (2017, 2018b, c),

64 Chen et al. (2019), Lui et al. (2019) and Kusunoki and Mizuta (2021) utilized the $20 \mathrm{~km}$ 
grid spacing version of MRI-AGCM (hereafter referred to as the $20-\mathrm{km}$ model) and the $60 \mathrm{~km}$ grid spacing version of MRI-AGCM (the $60-\mathrm{km}$ model). The details of these studies are summarized in Table 1 of Kusunoki and Mizuta (2021). Furthermore, Kamiguchi et al. (2006), Kitoh et al. (2009), Kusunoki et al. (2006), Kusunoki and Mizuta (2008), Endo et al. (2012), Kitoh and Endo (2016), Kusunoki (2018b) and Lui et al. (2019) projected future changes in heavy rainfall events with the $20-\mathrm{km}$ and $60-\mathrm{km}$ models. Focusing the tropical region, Fábrega et al. (2013), Nakaegawa et al. (2014a, b, c), Pinzón et al. (2017), Kusunoki et al. (2019) and Martínez et al. (2020) investigated future climate change projected with the $20-\mathrm{km}$ and $60-\mathrm{km}$ models.

Kusunoki et al. (2018a) compares the performance of the $20-\mathrm{km}$ and $60-\mathrm{km}$ models with those of AGCMs participated in the fifth phase of the Coupled Model Intercomparison Project (CMIP5; Taylor et al. 2012). The 20-km and 60-km models performs better than the CMIP5 AGCMs in simulating precipitation over East Asia (Kusunoki et al. 2018a). As for global distribution of precipitation, Kusunoki (2017) reported that the $60-\mathrm{km}$ model performs better than the CMIP5 AGCMs.

According to the protocol of the sixth phase of the Coupled Model Intercomparison Project (CMIP6; Eyring et al. 2016), the AMIP-type experiments were conducted by AGCMs which participated in the CMIP6. However, the reproducibility of the 20-km and $60-\mathrm{km}$ models in simulating precipitation is not yet compared with that of the CMIP6 AGCMs. Therefore, the aim of this paper is to verify the reproducibility of precipitation by the $20-\mathrm{km}$ and $60-\mathrm{km}$ models and the CMIP6 AGCMs. The performances of these models are compared focusing on geographical distribution of precipitation over the globe and over East Asia, the time evolution of summertime rainy 
season in East Asia region.

\section{Models and Experiments}

91

92

\subsection{The MRI-AGCM3.2 models}

The MRI-AGCM version 3.2 (MRI-AGCM3.2) has been developed for climate simulations with high horizontal resolution. In this study, we used the $20 \mathrm{~km}$ grid spacing version MRI-AGCM3.2S (the 20-km model) and the $60 \mathrm{~km}$ grid spacing version MRI-AGCM3.2H (the $60-\mathrm{km}$ model). Both version consist of 60 vertical levels. The top level is $0.01 \mathrm{hPa}$ equivalent to a altitude of about $80 \mathrm{~km}$. We adopted the cumulus convection scheme called the "YS scheme" (Yoshimura et al. 2015) which is developed from the method of Tiedtke (1989). Endo et al. (2012), Kusunoki (2016), Kusunoki (2018b, c) and Okada et al. (2017) used the 20-km model to investigate future precipitation changes in the Asian region. Kusunoki et al. (2019) utilized the 20-km model to project future precipitation changes in the tropics.

Because the 20-km model requires enormous supercomputer resources, large ensemble simulations is not easily feasible with the $20-\mathrm{km}$ model. In contrast, the calculation speed by the $60-\mathrm{km}$ model is 5 times larger than that of the $20-\mathrm{km}$ model. Ensemble simulations with the $60-\mathrm{km}$ model enable us to evaluate the uncertainty of future precipitation changes over Asian regions (Endo et al. 2012; Kusunoki and Mizuta 2013; Kusunoki 2018b, c; Kusunoki and Mizuta 2021), over the globe (Kusunoki 2017) and in the tropics (Kusunoki et al. 2019). Moreover, the 60-km model is used in the massive ensemble global warming simulations of about 100 members called the Database for Policy Decision-Making for Future Climate Change (d4PDF; Mizuta et al. 
111 2017; Ishii and Mori 2020; Kusunoki and Mizuta 2021).

112

\section{$113 \quad 2.2$ The CMIP6 atmospheric models}

114 We used 36 global atmospheric models (Table 1) which participated in the CMIP6

115 coordinated for the sixth assessment report of Intergovermental Panel on Climate

116 Change (IPCC AR6; IPCC 2021). The grid spacing of models ranges from 56 to $313 \mathrm{~km}$

117 (Table 1, the last column).

118

$119 \quad 2.3$ Sea surface temperature and sea ice

120 According to the procedure of the High Resolution Model Intercomparison Project

121 (HighResMIP ; Haarsma et al. 2016) implemented in the CMIP6, the MRI-AGCM3.2

122 models are forced by observed sea surface temperature (SST) and sea ice concentration

123 of the Hadley Centre Sea Ice and Sea Surface Temperature data set 2 (HadISST 2;

124 Rayner et al. 2003) for 20 years from year 1995 to 2014. We have conducted one

125 simulation by the $20-\mathrm{km}$ model (simulation name SPD) and four simulations by the 126 60-km model (simulation name HPD) giving four different atmospheric initial

127 conditions. The first character in simulation name indicates horizontal resolution of 128 model $(\mathrm{S} ; 20 \mathrm{~km}, \mathrm{H} ; 60 \mathrm{~km})$. The second character 'P' denotes present-day or historical

129 simulation. The third character 'D' indicates the simulation code for the HighResMIP.

130 These simulations correspond to AMIP-type simulations which evaluate the 131 performance of atmospheric models.

132 The CMIP6 global atmospheric models are also forced by the HadISST2 for 20 years

133 from year 1995 to 2014 according to the protocol of AMIP simulation in the Diagnostic, 
134 Evaluation and Characterization of Klima (DECK ; Eyring et al. 2016) experiments

135 (klima is Greek for "climate") within the frame work of the CMIP6. For further

136 technical details of external forcing such as aerosols and ozone for the HighResMIP

137 experiments and the AMIP simulation in CMIP6 DECK experiments, see Table 1 in

138 Haarsma et al. (2016).

139

\section{Observational data of precipitation}

141 We verified model performance using the One-Degree Daily data (1dd) of the

142 Global Precipitation Climatology Project (GPCP) v1.3 provided by Huffman et al.

143 (2001) for 22 years from 1997 to 2018. Horizontal grid size is 1.0 degree in longitude

144 and latitude corresponding to a distance of about $111 \mathrm{~km}$ at the equator. Considering the

145 horizontal resolutions of the $20-\mathrm{km}$ and $60-\mathrm{km}$ models are relatively higher than

146 generally used atmospheric models, we selected the GPCP $1 \mathrm{ddv} 1.3$ precipitation

147 because of its higher horizontal resolution. However, the GPCP $1 \mathrm{ddv} 1.3$ data only cover

148 the part of target period of model simulations from 1997 to 2014 . Pentad and monthly

149 data are derived from daily precipitation data. For the evaluation of model skills, all

150 model data were interpolated to the 1-degree grid of the GPCP 1dd.

151 The skill of model performance depends on the selection of observational data,

152 because observations have uncertainty (Sperber et al. 2013). The pentad data of the

153 GPCP v2.2 and the monthly data of the GPCP v2.3 provided by Adler et al. (2003) are 154 used for 20 years from 1995 to 2014 . These data cover the whole period of simulations 155 (1995-2014). The grid size is 2.5 degree which is equal to a spacing of about $278 \mathrm{~km}$ at 156 the equator. 

Analysis of Precipitation (CMAP) provided by Xie and Arkin (1997) are also selected

159 for 20 years through 1995 to 2014 . The grid spacing is 2.5 degree.

160 Table 3 summarizes the features of observational data for verification.

\section{Global precipitation}

\subsection{Geographical distribution}

164 The global distributions of annal precipitation (PAV, Table 3) are compared in Fig.1.

165 In the GPCP 1dd observation (Fig. 1a), precipitation is large over the Indian Ocean, 166 over the tropical area of the Pacific Ocean and the Atlantic Ocean, and over the Amazon.

167 Similar feature also appears in the GPCP data of 2.5 degree grid interval (Figs. 1b).

168 Precipitation by the CMAP of 2.5 degree grid interval (Fig. 1c) is larger than other 169 observations (Figs. 1a-b) over the Indian Ocean and the Maritime continent.

170 appears in other observations with some differences (Figs. 1b).

171 The 20-km model (SPD, Fig. 1d ) and the 60-km model (HPD, Fig. 1e) tend to

172 overestimate precipitation over the maritime continent and the South Pacific

173 Convergence Zone (SPCZ). This excessive precipitation is also found in the CMIP6 174 models (Fig. 1f-h). The overestimations of precipitation in the tropic over the Pacific 175 Ocean are also confirmed by bias distribution against the GPCP 1dd observation (Fig. 176 S1).

\subsection{Skill evaluation}

179 In Fig. 2, the performance of models as for PAV are quantitatively evaluated by 
objective skill measures based on the GPCP 1dd (green circle). The location of green

181 circle means perfect simulation. Figure 2 a shows the bias and root mean square error

182 (RMSE) of simulations. All models show positive bias partly due to the overestimation

183 of precipitation over the Pacific Ocean (Figs. 1 and S1). Black circles in Fig. 2 indicates

184 the multi-model ensemble (MME) average skill which is based on the 2-dimensional 185 global spatial distribution of precipitation constructed with the MME mean of CMIP6

186 models (Fig. 1f). Black squares in Fig. 2 display the average of the skill of each CMIP6

187 models (AVM). In the case of linear skill measures such as bias (Fig. 2a, horizontal

188 axis), the MME average is identical to the AVM. The biases of the $20-\mathrm{km}$ model (red S)

189 and the 60-km model (purple $\mathrm{H}$ ) are slightly larger than the MME average (black circle)

190 and the AVM (black square) of CMIP6 models (Fig. 2a).

191 The RMSE (Fig. 2a, vertical axis) of the $20-\mathrm{km}$ and $60-\mathrm{km}$ models are relatively 192 smaller than those of CMIP6 models. Since RMSE is a nonlinear skill measure, the

193 MME average (black circle) differs from the AVM (black square). The MME average 194 of CMIP6 models (black circle) is almost higher than the RMSEs of all individual 195 CMIP6 modes (black characters). This advantage of MME average is consistent with 196 previous studies such as Lambert and Boer (2001), Gleckler et al. (2008), Reichler and 197 Kim (2008), Kusunoki and Arakawa (2015) and Kusunoki (2018a).

198 To show the uncertainty of observation, the GPCP data of 2.5 degree grid interval 199 (green square) and the CMAP data of 2.5 degree grid interval (green diamond) are also 200 plotted as well as the GPCP1dd (green circle). The uncertainty (spread) among 201 observations (three green marks) are smaller than the magnitudes of bias and RMSE by 202 models. 
Figure $2 \mathrm{a}$ is the Taylor diagram (Taylor 2001) which demonstrates the spatial correlation coefficient between model simulations and observation as well as spatial standard deviation. The distance measured from the origin point is the standard

206 deviation of a simulated spatial distribution standardized by the observed standard 207 deviation. The radial distance of one means perfect simulation. The angle from the y-axis implies the spatial correlation coefficient. The perfect simulation coincides with the location of green circle. The spatial correlation coefficients of the 20-km (red S) and 60-km (purple H) models are relatively larger than those of individual CMIP6 models.

211 The spatial correlation coefficient of the MME average (black circle) of CMIP6 models

212 is almost higher than any other models. The symbols of all the models are plotted outer 213 area of the radius one quadrant. It means that spatial variability of all simulations is 214 overestimated.

215 In summary, Fig. 2 indicates that the reproducibility of the $20-\mathrm{km}$ and $60-\mathrm{km}$ models 216 are equivalent to or better than CMIP6 models in simulating global distribution of PAV. 217 This is similar to the result of previous studies on CMIP5 models (Kusunoki 2017 ; Fig. 218 1) which reported the advantage of the 60-model over CMIP5 atmospheric models in 219 simulating global distribution of PAV.

\subsection{Extreme precipitation events}

Table 3 shows the definition of extreme precipitation indices used for verification based on Frich et al. (2002). The maximum 5-day precipitation total (R5d) is often used to define heavy precipitation events leading to water related disaster such as inundation and landslide. The maximum 1-day precipitation total (R1d) is widely used to define 
extreme precipitation events happening once a year. On the other hand, maximum

227 consecutive dry days (CDD) is an index estimating the possibility of dry condition 228 ought. PAV is also included in Table 3 for comparison.

229 Figure 3 compares the reproducibility of the $20-\mathrm{km}$ and $60-\mathrm{km}$ models with those of

230 CMIP6 models as to four extreme indices. The spatial correlation coefficient of global 231 distribution of extreme precipitation events is selected as skill measure. As for PAV, the 232 spatial correlation coefficients of the $20-\mathrm{km}$ and $60-\mathrm{km}$ models are almost the same as 233 that of the best CMIP6 model and the MME average (black circle). In the case of R5d, 234 the skill of $60-\mathrm{km}$ models (purple lines) are better than the AVM of CMIP6 models 235 (thick long black line), but the skill of $20-\mathrm{km}$ model (red line) is comparable to the 236 AVM. As for R1d, the skill of the $20-\mathrm{km}$ model (red line) is lower than the AVM. This

237 might be partly attributed to the lower horizontal resolution of the GPCP 1dd 238 observation $(111 \mathrm{~km})$ as compared to that of the $20-\mathrm{km}$ model. In the case of CDD, the 239 skills of $20-\mathrm{km}$ and $60-\mathrm{km}$ models are almost near to those of CMIP6 models. In terms 240 of RMSE, the advantage of the $20-\mathrm{km}$ and $60-\mathrm{km}$ models are recognized only for PAV 241 (Figure not shown).

\subsection{Skill dependence on horizontal resolution}

244 Figure 4 illustrates how the model skill depends on the horizontal resolution of 245 models in the case of spatial correlation coefficient for global PAV. Models with small 246 grid spacing, namely models with higher horizontal resolution, tend to show higher skill.

247 The correlation coefficient between grid spacings and spatial correlations coefficient for 248 global PAV is -0.463 which exceeds the $99 \%$ statistical significance level. Figure 5 
249 shows how model performance depends upon on grid spacing for all four extreme

250 events (Table 3). All four negative correlation suggests the advantage of higher 251 horizontal resolution models over low resolution models, but statistical significance 252 above $99 \%$ level is only recognized for PAV and R5d.

\section{Precipitation over East Asia}

\subsection{Geographical distribution}

The rainy season over Japan (the Baiu) starts in the middle of May and terminates in

257 the end of July. Figure 2 compares observed precipitations with simulated precipitations 258 in June. In the GPCP 1ddv1.3 observation (Fig. 6a), precipitation is larger over the 259 Taiwan island, the southern part of China, the East China Sea and to the south of Japan, 260 which corresponds to the Baiu rain band. This rainy zone is also presented in other 261 observations with some differences (Figs. 6b-c). The 20-km model correctly reproduces 262 the location of the Baiu zone, but the precipitation amount is apparently underestimated 263 (Fig. 6d). The simulation by the 60-km model (Fig. 6e) is nearly the same as that by the 264 20-km model (Fig. 6d) with larger precipitation amount to the south of Japan as compared to the $20-\mathrm{km}$ model.

266 The MME average of CMIP6 models also underestimates precipitation of the Baiu 267 rain band (Fig. 6f). The spatial coefficient $\mathrm{C}$ of the best CMIP6 model is high as 0.837 , 268 but precipitation is still underestimated (Fig. 6g). The worst CMIP6 model shows erroneous excessive precipitation to the south of $25^{\circ} \mathrm{N}$ (Fig. 6h).

Figure 7 shows the objective skill scores of models for June precipitation over East Asia (Fig. 6). Most models underestimate precipitation (Fig. 7a, horizontal axis). In 
terms of RMSE (Fig. 7a, vertical axis), the RMSE of the 20-km and 60-km models are

273 relatively smaller than CMIP6 models and is smaller than the MME average of CMIP6 274 models (black circle). In the Taylor diagram (Fig. 7b), almost entire models are 275 displayed inside the radius one quadrant. This mans the underestimation of spatial 276 variability. The spatial correlation coefficients of the $20-\mathrm{km}$ and $60-\mathrm{km}$ models are 277 relatively larger than those of CMIP6 models.

278 In the case of July which corresponds to the later half of the Baiu season, the 279 reproducibility of the $20-\mathrm{km}$ and $60-\mathrm{km}$ models are also higher than CMIP6 models in 280 simulating July precipitation over East Asia region with respect to bias, spatial 281 variability and spatial correlation coefficient (Figs. S2-S3). Models with higher 282 horizontal resolution tend to perform better than those with lower resolution in 283 simulating monthly precipitation in warmer season over East Asia (Fig. S4).

284 The superiority of the $20-\mathrm{km}$ and $60-\mathrm{km}$ models over CMIP6 models in simulating 285 summer precipitation is similar to the results by Kusunoki (2018a) with respect to 286 CMIP5 models.

\subsection{Seasonal march of the rainy season over Japan}

289 Figure 8 depicts the seasonal march of the Japanese rainy season (the Baiu) based on 290 longitudinal averaged pentad precipitation over Japan. In the GPCP 1ddv1.3 observation 291 (Fig. 8a), the Baiu starts in the middle of May at latitude around $25^{\circ} \mathrm{N}$. The Baiu 292 migrates northward till the middle of July at latitude around $37^{\circ} \mathrm{N}$. Other observations 293 show similar northward migration of the Baiu (Figs. 8b-c). In the 20-km model (Fig. 8d), 294 precipitation of the Baiu is underestimated and northward migration is not clear. The 
60-km model (Fig. 8e) seems to simulate larger precipitation in the Baiu season than the 20-km model (Fig. 8d). The MME average CMIP8 models apparently underestimate

297 precipitation and the location of the Baiu is shifted to north as compared to observation

298 (black contour). Even the best CMIP6 model underestimate precipitation amount of the

299 Baiu (Fig. 8g). The worst model shows the erroneous location of Baiu (Fig. 8h).

300 In terms of objective skill scores (Fig. 9), most models underestimate precipitation

301 (Fig. 9a, horizontal axis). The RMSEs of the $20-\mathrm{km}$ and $60-\mathrm{Km}$ model are relatively

302 less than those of individual CMIP6 models and the MME average of CMIP6 model

303 (Fig. 9a, vertical axis). Most models underestimate spatial variability (Fig. 9b). The

304 spatial correlation coefficients of the $20-\mathrm{km}$ and $60-\mathrm{km}$ models are relatively higher 305 than those of individual CMIP6 models and the MME average of CMIP6 model (Fig.

306 9b). Models with higher resolution tend to perform better than those with lower 307 horizontal resolution in simulating the seasonal march of rainy season over Japan (Fig.

308 10). The correlation coefficient between grid spacings and spatial correlations 309 coefficient for seasonal march of the Baiu is -0.520 which is larger than the $99 \%$ 310 statistical significance level.

311 In summary, the reproducibility of the $20-\mathrm{km}$ and $60-\mathrm{km}$ models is better than

312 CMIP6 models in simulating the seasonal march of the Japanese rainy season. This is 313 similar to the results by Kusunoki (2018a) with respect to CMIP5 models.

\subsection{Extreme precipitation events}

316 Figure 11 compares the performance of models in simulating extreme precipitation

317 events over East Asia. The skills of $20-\mathrm{km}$ and $60-\mathrm{km}$ models are equivalent to or better 
318 than those of CMIP6 models for all four indices. The advantage of the $20-\mathrm{km}$ and

319 60-km models (Fig. 11) are more evident than global case (Fig. 3).

320 Figure 12 depicts how the model skill depends on the horizontal resolution of models

321 in the case of spatial correlation coefficient for four extreme precipitation indices over

322 East Asia. Large negative correlation coefficients for all four indices imply the

323 advantage of higher horizontal resolution models over lower resolution models.

324 Magnitude of statistical correlation coefficients and significance levels of all four

325 indices over East Asia (Fig. 12) are larger than those over the globe (Fig. 5). This

326 suggests that the advantage of higher horizontal resolution models is much more evident

327 over East Asia than over the globe.

328 Why higher horizontal resolution models performs better over East Asia region? The

329 Baiu rain band is characterized by multi-scale phenomena where the meso-scale 330 disturbances (less than $100 \mathrm{~km}$ ) are embedded in larger synoptic scale structure 331 (Ninomiya and Akiyama 1992). Intense rainfall events often occur in such small scale

332 structures in the Baiu rain band. Tropical cyclones are also characterized by small scale 333 structure such as rain bands and convective cells embedded in larger synoptic scale 334 structure (Houze 2010). Intense rainfall events over East Asia is often caused by 335 meso-scale convective disturbances associated with the Baiu rainy season and tropical 336 cyclones (typhoons). Apparently, higher horizonal resolution models have the advantage 337 over lower resolution models in simulating these small scale disturbances.

\section{Comparison with CMIP5 models}

340 Figure 13 compares the performances of the $20-\mathrm{km}$ and $60-\mathrm{km}$ models with those of 
341 CMIP5 and CMIP6 global atmospheric models with respect to the global distribution of

342 annual precipitation. All the simulations are based on AMIP-type experiments. Since

343 most CMIP5 model simulations terminate at year 2008, the target period of comparison

344 is selected for 20 years from 1981 to 2000. In Fig. 12, the performances of CMIP6

345 models are better than those of CMIP5 models in terms of AVM and MME. CMIP6 was

346 accomplished about 10 years after CMIP5. Figure 12 suggests the climate models were

347 apparently improved during this last decade due to continuous and great efforts by

348 climate modelling scientists. The $20-\mathrm{km}$ and $60-\mathrm{km}$ models perform relatively better

349 than CMIP5 and CMIP6 models in simulating the spatial pattern of global annual

350 precipitation.

351 As for monthly precipitation over East Asia, also the performances of CMIP6 models

352 are better than those of CMIP5 models (Fig. S5). The 20-km and 60-km models perform

353 relatively better than CMIP5 and CMIP6 models especially in warm season (Fig. S5).

354 The performance of $20-\mathrm{km}$ and $60-\mathrm{km}$ models are better than or equal to CMIP5 and

355 CMIP6 models in simulating R1d over East Asia (Fig. S6). The 20-km and 60-km

356 models perform relatively better than CMIP5 and CMIP6 models in simulating the

357 seasonal march of Japanese rainy season (Fig. S7).

358

3597 Conclusions

$360 \quad$ Our results are summarized as follows.

361 1. The performance of MRI-AGCM3.2 models is higher than or equal to CMIP6

362 atmospheric models with respect to the geographical distribution of annual 363 precipitation and intense precipitation over the globe. 
364 2. Models with higher horizontal resolution perform better than those with lower 365 resolution in simulating global precipitation.

366 3. The reproducibility of MRI-AGCM3.2 models is higher than or comparable to 367 CMIP6 atmospheric models as to monthly precipitation, the seasonal march of 368 Japanese rainy season and extreme precipitation events over East Asia.

369 4. Models with higher horizontal resolution perform better than those with lower 370 resolution in simulating precipitation over East Asia.

371 5. The advantage of higher horizontal resolution models over lower resolution models is 372 more evident over East Asia than over the globe.

373

374 Acknowledgment

375 This work was supported by the Integrated Research Program for Advancing Climate 376 Models (TOUGOU), Grant Number JPMXD0717935561, from the Ministry of 377 Education, Culture, Sports, Science and Technology (MEXT), Japan. This work was 378 also supported by Japan Society for the Promotion of Science(JSPS) KAKENHI Grant 379 Numbers 20K12154 and 21K03670. We acknowledge the international modeling groups 380 participated to CMIP6, the Earth System Grid Federation (ESGF) which distributes data, 381 and the Working Group on Coupled Modeling (WGCM) Infrastructure Panel which is 382 coordinating and encouraging the development of the infrastructure needed to archive 383 and deliver dataset.

\section{Statements and Declarations}

386 The authors declare no competing interests. 


\section{Data availability}

389 The MRI-AGCM3.2 data are available at the website of the Earth System Grid 390 Federation (ESGF); https://esgf.llnl.gov/

391 The CMIP6 data are available at the website for the sixth phase of the Coupled Model

392 Intercomparison Project (CMIP6) supplied by the Program for Climate Model 393 Diagnosis and Intercomparison (PCMDI); https://pcmdi.llnl.gov/CMIP6/

394

395 


\section{References}

397 Adler RF, Huffman GJ, Chang A, Ferrano R, Xie PP, Janowiak J, Rudolf B, Schneider U, Curtis S, Bolvin D, Gruber A, Susskind J, Arkin P, Nelkin E (2003) The version-2 global precipitation climatology preject (GPCP) monthly precipitation analysis (1979-present). $\mathrm{J}$

Hydrometeor 4:1147-1167. doi:10.1175/1525-7541(2003)004<1147:TVGPCP >2.0.CO;2

Chen CA, Hsu HH, Hong CC, Chiu PG, Tu CY, Lin SJ, Kitoh A (2019) Seasonal 403 precipitation change in the western North Pacific and East Asia under global warming in two high-resolution AGCMs. Clim Dyn 53:5583-5605. doi:10.1007/s00382-019-04883-1

Endo H, Kitoh A, Ose T, Mizuta R, Kusunoki S (2012) Future changes and uncertainties in Asian precipitation simulated by multiphysics and multi-sea surface temperature ensemble experiments with high-resolution Meteorological Research Institute atmospheric general circulation models (MRI-AGCMs). J Geophys Res

411 Eyring V, Bony S, Meehl GA, Senior CA, Stevens B, Stouffer RJ, Taylor KE (2016)

412 Overview of the Coupled Model Intercomparison Project Phase 6 (CMIP6) 413 experimental design and organization. Geosci Model Dev 9:1937-1958. 414 doi:10.5194/gmd-9-1937-2016

415 Fábrega J, Nakaegawa T, Pinzón R, Nakayama K, Arakawa O, SOUSEI Theme-C 416 modeling group (2013) Hydroclimate projections for Panama in the 21st Century. $417 \quad$ Hydrol Res Lett 7:23-29. doi:10.3178/hrl.7.23

418 Frich P, Alexander LV, Della-Marta P, Gleason B, Haylock M, Klein Tank AMG, 

Peterson T (2002) Observed coherent changes in climatic extremes during the second half of the twentieth century. Clim Res 19:193-212. doi:10.3354/cr019193

Gleckler PJ, Taylor KE, Doutriaux C (2008) Performance metrics for climate models. J Geophys Res 113:D06104. doi:10.1029/2007JD008972

423

424

425

426

427

428

429

430

431

432

433

434

435

436

437

438

439

440

441

Haarsma RJ, Roberts MJ, Vidale PL, Senior CA, Bellucci A, Bao Q, Chang P, Corti S, Fučkar NS, Guemas V, von Hardenberg J, Hazeleger W, Kodama C, Koenigk T, Leung LR, Lu J, Luo J-J, Mao J, Mizielinski MS, Mizuta R, Nobre P, Satoh M, Scoccimarro E, Semmler T, Small J, von Storch JS (2016) High Resolution Model Intercomparison Project (HighResMIP v1.0) for CMIP6, Geosci. Model Dev 9: 4185-4208. doi:10.5194/gmd-9-4185-2016

Houze RA Jr (2010) Clouds in tropical cyclones. Mon Wea Rev 138:293-344. doi: 10.1175/2009MWR2989.1

Huffman GJ, Adler RF, Morrissey MM, Bolvin DT, Curtis S, Joyce R, McGavock B, Susskind J (2001) Global precipitation at one-degree daily resolution from multisatellite observations. J Hydrometeor 2:36-50. doi: 10.1175/1525-7541(2001)002\%3c003 6:GPAOD D\%3e2.0.CO;2

IPCC (Intergovernmental Panel on Climate Change) (2021) Climate change 2021: The Physical Science Basis. Contribution of Working Group I to the Sixth Assessment Report of the Intergovernmental Panel on Climate Change. In: Masson-Delmotte V, Zhai P, Pirani A, Connors SL, Péan C, Berger S, Caud N, Chen Y, Goldfarb L, Gomis MI, Huang M, Leitzell K, Lonnoy E, Matthews JBR, Maycock TK, Waterfield T, Yelekçi O, Yu R, Zhou B (eds). Cambridge University Press. in press

Ishii M, Mori N (2020) d4PDF: large-ensemble and high-resolution climate simulations 
444 Kamiguchi K, Kitoh A, Uchiyama T, Mizuta R, Noda A (2006) Changes in 445 precipitation-based extremes indices due to global warming projected by a global 446 20-km-mesh atmospheric model. SOLA 2:64-67. doi:10.2151/sola.2006-017

447 Kang IS, Jin K, Wang B, Lau KM, Shukla J, Krishnamurthy V, Schubert SD, Wailser 448 DE, Stern WF, Kitoh A, Meehl GA, Kanamitsu M, Galin VY, Satyan V, Park CK, 449 Liu Y (2002) Intercomparison of the climatological variations of Asian summer 450 monsoon precipitation simulated by 10 GCMs. Clim Dyn 19:383-395. doi:10.1007/s00382-002-0245-9

452 Kitoh A, Endo H (2016) Changes in precipitation extremes projected by a $20-\mathrm{km}$ mesh 453 global atmospheric model. Weather Clim Extrem 11:41-52. doi:10.1016/j.wace.2015.09.001

Kitoh A, Kusunoki S (2008) East Asian summer monsoon simulation by a 20-km mesh AGCM. Clim Dyn 31:389-401. doi:10.1007/s00382-007-0285-2

Kitoh A, Ose T, Kurihara K, Kusunoki S, Sugi M, KAKUSHIN Team-3 Modeling 458 Group (2009) Projection of changes in future weather extremes using super-high-resolution global and regional atmospheric models in the KAKUSHIN

Kusunoki S (2017) Future changes in global precipitation projected by the atmospheric 463 model MRI-AGCM3.2H with a 60-km size. Atmosphere 8:93. https ://doi.org/10.3390/atmos 8050093 
465 Kusunoki S (2018a) Is the global atmospheric model MRI-AGCM3.2 better than the 466 CMIP5 atmospheric models in simulating precipitation over East Asia? Clim Dyn. doi:10.1007/s0038 2-016-3335-9

468 Kusunoki S (2018b) Future changes in precipitation over East Asia projected by the global atmospheric model MRI-AGCM3.2. Clim Dyn doi:10.1007/s0038 2-016-3499-3

Kusunoki S (2018c) How will the onset and retreat of rainy season over East Asia change in future? Atm Sci Let 19:e824, doi: 10.1002/asl.824

Kusunoki S, Arakawa O (2015) Are CMIP5 models better than CMIP3 models in simulating precipitation over East Asia? J Clim 28:5601-5621. doi:10.1175/JCLI-D-14-00585.1

Kusunoki S, Mizuta R (2008) Future changes in the Baiu rain band projected by a 20-km mesh global atmospheric model: sea surface temperature dependence. SOLA 4:85-88, doi:10.2151/sola.2008-022

Kusunoki S, Mizuta R (2012) Comparison of near future (2015-2039) changes in the 480 East Asian rain band with future (2075-2099) changes projected by global 481 atmospheric models with $20-\mathrm{km}$ and $60-\mathrm{km}$ grid size. SOLA 8:73-76,

483 Kusunoki S, Mizuta R (2013) Changes in precipitation intensity over East Asia during the 20th and 21 st centuries simulated by a global atmospheric model with a $60 \mathrm{~km}$ grid size. J Geophys Res Atmos 118:11007-11016. https ://doi.org/10.1002/jgrd.50877

487 Kusunoki S, Mizuta R (2021) Future changes in rainy season over East Asia projected 
by massive ensemble simulations with a high-resolution global atmospheric model. J Meteor Soc Jpn 99:79-100. doi:10.2151/jmsj.2021-005

Kusunoki S, Sugi M, Kitoh A, Kobayashi C, Takano K (2001) Atmospheric seasonal predictability experiments by the JMA AGCM. J Meteorol Soc Jpn 79:1183-1206. doi:10.2151/jmsj.79.1183

Kusunoki S, Yoshimura J, Yoshimura H, Noda A, Oouchi K, Mizuta R (2006) Change 494 of Baiu rain band in global warming projection by an atmospheric general

Kusunoki S, Mizuta R, Matsueda M (2011) Future changes in the East Asian rain band 498 projected by global atmospheric models with $20-\mathrm{km}$ and $60-\mathrm{km}$ grid size. Clim Dyn 37:2481-2493. doi:10.1007/s00382-011-1000-x

Kusunoki S, Nakaegawa T, Pinzón R, Sanchez-Galan JE, Fábrega JR (2019) Future

Lau K-M, Li M-T (1984) The monsoon of East Asia and its global association-a 504 survey.

Bull Am Meteorol

Soc 65:114-125. doi:10.1175/1520-0477(1984)065<0114:TMOEAA>2.0.CO;2

Lau KM, Yang S (1996) Seasonal variation, abrupt transition, and intraseasonal 508 variability associated with the Asian summer monsoon in the GLA GCM. J Clim 9:965-985. doi:10.1175/1520-0442(1996)009<0965:SVATAI $>2.0 . C O ; 2$

Lau KM, Kim JH, Sud Y (1996) Intercomparison of hydrologic processes in AMIP 510 GCMs. Bull $\mathrm{Am}$ Meteorol Soc 77:2209-2227. 
512 Liang XZ, Wang WC, Samel AN (2001) Biases in AMIP model simulations of the east

513 China monsoon system. Clim Dyn 17:291-304. doi:10.1007/s003820000136

514 Liang XZ, Wang WC, Samel AN (2001) Biases in AMIP model simulations of the east

515 China monsoon system. Clim Dyn 17:291-304. doi:10.1007/s003820000136

516 Lui YS, Tam CY, Lau NC (2019) Future changes in Asian summer monsoon

517 precipitation extremes as inferred from 20-km AGCM simulations. Clim Dyn $518 \quad 52: 1443-1459$. doi:10.1007/s00382-018-4206-3

519 Martínez MM, Nakaegawa T, Pinzón TR, Kusunoki S, Gordón R, Sanchez-Galan JE, 520 (2020) Using a statistical crop model to predict maize yield by the end-of-century for the Azuero region in Panama. Atmosphere 11:1097, doi:10.3390/atmos11101097

Mizuta R, Murata A, Ishii M, Shiogama H, Hibino K, Mori N, Arakawa O, Imada Y, Yoshida K, Aoyagi T, Kawase H, Mori M, Okada Y, Shimura T, Nagatomo T, Ikeda M, Endo H, Nosaka N, Arai M, Takahashi C, Tanaka K, Takemi T, Tachikawa Y, Temur K, Kamae Y, Watanabe M, Sasaki H, Kitoh A, Takayabu I, Nakakita E, Kimoto M (2017) Over 5,000 years of Ensemble Future Climate Simulations by 60-km Global and 20-km Regional Atmospheric Models. Bull Amer Meteor Soc 98:1383-1398. doi:10.1175/BAMS-D-16-0099.1

530 Nakaegawa T, Kitoh A, Ishizaki Y, Kusunoki S, Murakami H (2014a) Caribbean 531 low-level jets and accompanying moisture fluxes in a global warming climate 532 projected with CMIP3 multi-model ensemble and fine-mesh atmospheric general circulation models. Int J Climatol 34:964-977. doi:10.1002/joc.3733 
534 Nakaegawa T, Kitoh A, Kusunoki S, Murakami H, Arakawa O (2014b) Hydroclimate 535 change over Central America and the Caribbean in a global warming climate 536 projected with $20-\mathrm{km}$ and $60-\mathrm{km}$ mesh MRI atmospheric general circulation models. 537 Pap Meteorol Geophys 65:15-33. doi:10.2467/mripa pers.65.15

538 Nakaegawa T, Kitoh A, Murakami H, Kusunoki S (2014c) Maximum 5-day rainfall total 539 and the maximum number of consecutive dry days over Central America in the 540 future climate projected by an atmospheric general circulation model with three 541 different horizontal resolutions. Theor Appl Climatol 116:155-168. doi:10.1007/s0070 4-013-0934-9

543 Ninomiya K, Akiyama T (1992) Multi-scale features of Baiu, the summer monsoon over Japan and the East Asia. J Meteor Soc Jpn 70:467-495. doi:10.2151/jmsj1965.70.1B_467

546 Okada Y, Takemi, Ishikawa H, Kusunoki S, Mizuta R (2017) Future changes in atmospheric conditions for the seasonal evolution of the Baiu as revealed from projected AGCM experiments. J Meteor Soc Jpn 95:239-260.

550 Pinzón R, Hibino K, Takayabu I, Nakaegawa T (2017) Virtual experiencing future

Randall DA, Wood RA, Bony S, Colman R, Fichefet T, Fyfe J, Kattsov V, Pitman A, 554 Shukla J, Srinivasan J, Stouffer RJ, Sumi A, Taylor KE (2007) Climate Models and Their Evaluation. Climate Change 2007: The Physical Science Basis. Contribution of Working Group I to the Fourth Assessment Report of the 

University Press, Cambridge, United Kingdom and New York, NY, USA.

Rayner NA, Parker DE, Horton EB, Folland CK, Alexander LV, Rowell DP, Kent EC, Kaplan A (2003) Global analyses of sea surface temperature, sea ice, and night marine air temperature since the late nineteenth century. J Geophys Res 108(D14):4407. doi:10.1029/2002JD002670

Reichler T, Kim J (2008) How well do coupled models simulate today's climate? Bull Am Meteorol Soc 89:303-311. doi:10.1175/BAMS-89-3-303

Sperber KR, Annamalai H, Kang IS, Kitoh A, Moise A, Turner AG, Wang B, Zhou T (2013) The Asian summer monsoon: an intercomparison of CMIP5 vs. CMIP3 simulations of the late 20th century. Clim Dyn 41:2711-2744. doi:10.1007/S00382-012-1607-6

Taylor KE (2001) Summarizing multiple aspects of model performance in a single diagram. J Geophys Res 106:7183-7192. doi:10.1029/2000JD900719

Taylor KE, Stouffer RJ, Meehl GA (2012) An Overview of CMIP5 and the Experiment Design. Bull Amer Meteor Soc 93:485-498. d:10.1175/BAMS-D-11-00094.1

574 Tiedtke M (1989) A comprehensive mass flux scheme for cumulus parameterization in large-scale models. Mon Weather Rev 117:1779-1800.

577 Xie P, Arkin P (1997) Global precipitation: a 17-year monthly analysis based on gauge 578 observations, satellite estimates and numerical model outputs. Bull Am Meteorol Soc 78:2539-2558. doi:10.1175/1520-0477(1997)078<2539:GPAYMA>2.0.CO;2 
580 Yoshimura H, Mizuta R, Murakami H (2015) A spectral cumulus parameterization

581 scheme interpolating between two convective updrafts with semi-lagrangian 582 calculation of transport by compensatory subsidence. Mon Weather Rev $583 \quad$ 143:597-621. doi:10.1175/MWR-D-14-00068.1

584 
Table 1 Features of 36 CMIP6 models used in this study

\begin{tabular}{|c|c|c|c|c|c|c|}
\hline \multirow[t]{2}{*}{$\overline{\text { No. I }}$} & \multirow[t]{2}{*}{ Label } & \multirow{2}{*}{$\begin{array}{l}\text { Name in Table AII.5 of } \\
\text { IPCC (2021) }\end{array}$} & \multirow{2}{*}{$\begin{array}{l}\text { Horizontal } \\
\text { resolution and } \\
\text { vertial levels }^{\mathrm{a}}\end{array}$} & \multicolumn{2}{|c|}{ Number of grids } & \multirow{2}{*}{$\begin{array}{l}\text { Longitudinal grid spacing } \\
(\mathrm{km}) \text { at the equator }{ }^{\mathrm{b}}\end{array}$} \\
\hline & & & & Longitude & Latitude & \\
\hline 1 & $\mathrm{a}$ & ACCESS-CM2 & G064L85 & 192 & 144 & 208 \\
\hline 2 & $\mathrm{~b}$ & ACCESS-ESM1-5 & G064L38 & 192 & 145 & 208 \\
\hline 3 & $\mathrm{c}$ & BCC-CSM2-MR & $\mathrm{T} 106 \mathrm{~L} 46$ & 320 & 160 & 125 \\
\hline 4 & d & BCC-ESM1 & T042L26 & 128 & 64 & 313 \\
\hline 5 & $\mathrm{e}$ & CAMS-CSM1-0 & $\mathrm{T} 106 \mathrm{~L} 31$ & 320 & 160 & 125 \\
\hline 6 & $f$ & CanESM5 & T042L49 & 128 & 64 & 313 \\
\hline 7 & g & CESM2 & G096L32 & 288 & 192 & 139 \\
\hline 8 & $\mathrm{~h}$ & CESM2-FV2 & G048L32 & 144 & 96 & 278 \\
\hline 9 & $\mathrm{i}$ & CESM2-WACCM & G096L 70 & 288 & 192 & 139 \\
\hline 10 & $\mathrm{j}$ & CMCC-CM2-SR5 & G096L30 & 288 & 192 & 139 \\
\hline 11 & $\mathrm{k}$ & CNRM-CM6-1 & T085L91 & 256 & 128 & 156 \\
\hline 12 & 1 & CNRM-CM6-1-HR & T240L91 & 720 & 360 & 56 \\
\hline 13 & $\mathrm{~m}$ & CNRM-ESM2-1 & T085L91 & 256 & 128 & 156 \\
\hline 14 & $\mathrm{n}$ & EC-Earth3 & T170L91 & 512 & 256 & 78 \\
\hline 15 & o & EC-Earth3-AerChem & T170L91 & 512 & 256 & 78 \\
\hline 16 & $\mathrm{p}$ & EC-Earth3-CC & T170L91 & 512 & 256 & 78 \\
\hline 17 & q & EC-Earth3-Veg & T170L91 & 512 & 256 & 78 \\
\hline 18 & $\mathrm{r}$ & FGOALS-f3-L & G096L32 & 288 & 180 & 139 \\
\hline 19 & $\mathrm{~s}$ & FGOALS-g3 & T060L26 & 180 & 80 & 222 \\
\hline 20 & $\mathrm{t}$ & GFDL-CM4 & G096L33 & 288 & 180 & 139 \\
\hline 21 & $\mathrm{u}$ & GFDL-ESM4 & G096L33 & 288 & 180 & 139 \\
\hline 22 & $\mathrm{v}$ & IITM-ESM & T064L64 & 192 & 94 & 208 \\
\hline 23 & $\mathrm{w}$ & INM-CM4-8 & G060L21 & 180 & 120 & 222 \\
\hline 24 & $\mathrm{x}$ & INM-CM5-0 & G060L21 & 180 & 120 & 222 \\
\hline 25 & $\mathrm{y}$ & IPSL-CM6A-LR & G048L79 & 144 & 143 & 278 \\
\hline 26 & $\mathrm{z}$ & KIOST-ESM & G064L32 & 192 & 96 & 208 \\
\hline 27 & A & MIROC6 & T085L81 & 256 & 128 & 156 \\
\hline 28 & B & MIROC-ES2L & T042L40 & 128 & 64 & 313 \\
\hline 29 & $\mathrm{C}$ & MPI-ESM1-2-HAM & T063L47 & 192 & 96 & 208 \\
\hline 30 & $\mathrm{D}$ & MPI-ESM1-2-HR & T128L95 & 384 & 192 & 104 \\
\hline 31 & $\mathrm{E}$ & MPI-ESM1-2-LR & T063L47 & 192 & 96 & 208 \\
\hline 32 & $\mathrm{~F}$ & MRI-ESM2-0 & T106L80 & 320 & 160 & 125 \\
\hline 33 & G & NESM3 & T063L47 & 192 & 96 & 208 \\
\hline 34 & $\mathrm{H}$ & NorCPM1 & G048L26 & 144 & 96 & 278 \\
\hline 35 & $\mathrm{~J}$ & NorESM2-LM & G048L32 & 144 & 96 & 278 \\
\hline \multirow[t]{3}{*}{36} & K & SAM0-UNICON & G096L30 & 288 & 192 & 139 \\
\hline & $\mathrm{S}$ & MRI-AGCM3.2S & T639L60 & 1920 & 960 & 21 \\
\hline & $\mathrm{H}$ & MRI-AGCM3.2H & T213L60 & 640 & 320 & 63 \\
\hline
\end{tabular}

${ }^{a}$ Gmeans grid model. Two figures following after $\mathrm{G}$ indicate corresponding spectral wave number.

Figures following after $\mathrm{T}$ indicate the triangular runcation at the corresponding spectral wavenumber.

Two fugures follwing after $\mathrm{L}$ indicate vertical levels.

b The minimum is $56 \mathrm{~km}$; CNRM-CM6-1-HR.

The maximum is $313 \mathrm{~km}$; BCC-ESM1, CanESM5, MIROC-ES2L.

CMIP6 stands for the sixth phase of the Coupled Model Intercomparison Project. 
Table 2 Observations of precipitation used for verification

\begin{tabular}{llclll}
\hline Name & $\begin{array}{l}\text { Time } \\
\text { resolution }\end{array}$ & $\begin{array}{l}\text { Spatial } \\
\text { resolution } \\
\text { in degree }\end{array}$ & $\begin{array}{l}\text { Period } \\
\text { (Number of years) }\end{array}$ & Region & Reference \\
\hline GPCP 1ddv1.3 & Day & 1.0 & $1997-2018(22)$ & Globe & Huffman et al. (2001) \\
GPCP v2.2 & Pentad & 2.5 & $1995-2014(20)$ & Globe & Adler et al. (2003) \\
CMAP v1701 & Pentad & 2.5 & $1995-2014(20)$ & Globe & Xie and Arkin (1997) \\
GPCP v2.3 & Month & 2.5 & $1995-2014(20)$ & Globe & Adler et al. (2003) \\
CMAP v1705 & Month & 2.5 & $1995-2014(20)$ & Globe & Xie and Arkin (1997) \\
\hline
\end{tabular}

GPCP stands for the Global Precipitation Climatology Project.

1dd stands for the One-Degree Daily data.

586 CMAP stands for the Climate Prediction Center Merged Analysis of Precipitation.

Table 3 Indices for extreme events of precipitation

\begin{tabular}{llll}
\hline Index & Name & Definition & Unit \\
\hline PAV & Annual mean precipitation & Precipitation average for a year & mm day $^{-1}$ \\
R5d & Maximum 5-day cumulated precipitation & $\begin{array}{l}\text { Maximum of consecutive 5-day precipitation in a } \\
\text { year }\end{array}$ & mm \\
R1d & Maximum 1-day precipitation & Maximum of daily precipitation In a year & mm \\
CDD & Maximum consecutive dry days & $\begin{array}{l}\text { Maximum number of consecutive dry days } \\
\text { (precipitation }<1 \mathrm{~mm} \text { ) in a year }\end{array}$ & day \\
\hline
\end{tabular}


(a) GPCP $1 \mathrm{ddv} 1.3$

1997-2018, 22 years

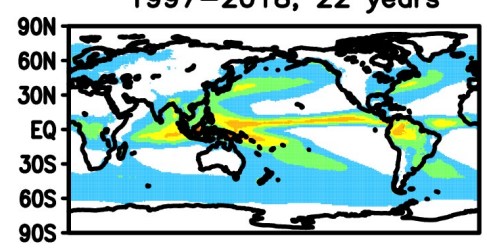

(d) SPD

R:1.04 B:0.37 C:0.918

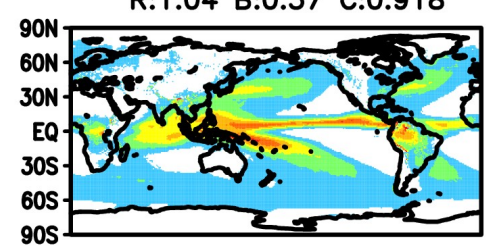

(f) CMIP6 MME

R:0.79 B:0.28 C:0.933

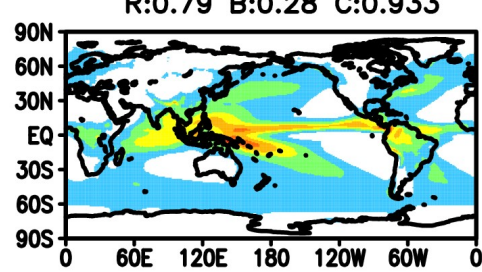

(b) GPCP v2.3

1995-2014, 20 years

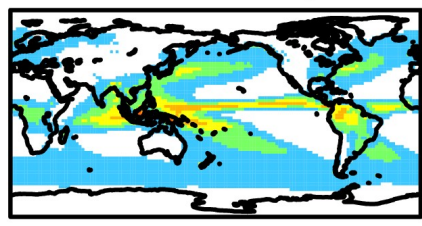

(e) HPD

R:0.91 B:0.32 C:0.931

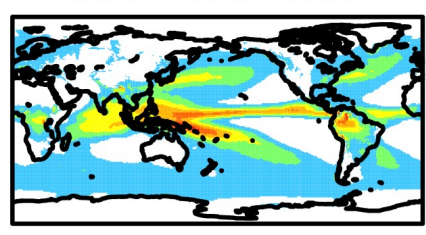

(g) Best EC-Earth3

R:0.83 B:0.22 C:0.931

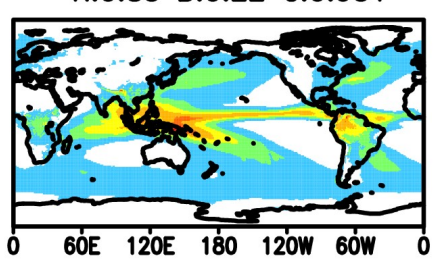

(c) CMAP V1705

1995-2014, 20 years
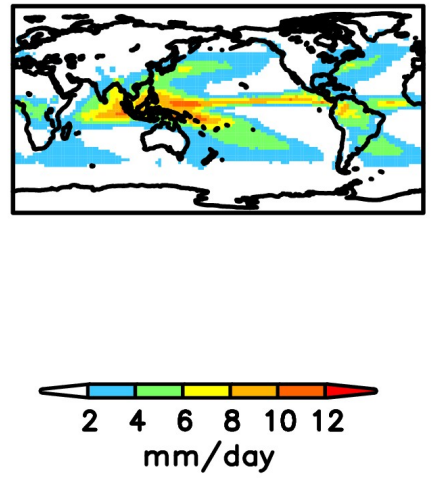

(h) Worst IITM-ESM R:1.54 B:0.33 C:0.752

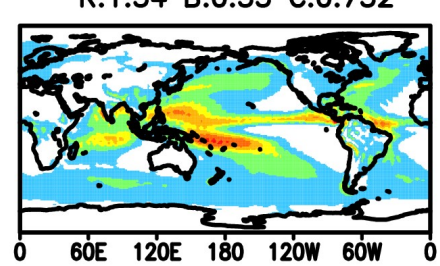

593

594 Fig. 1 The global distributions of climatological annual precipitation PAV (mm day $\left.{ }^{-1}\right)$.

595 a-c Observations (Table 2). d SPD. Averaged period is 20 years from 1995 through

596 2014. e Similar to d but for HPD. The first member of ensemble simulations is plotted.

597 f Same as $\mathbf{d}$ but for the MME (multi-model ensemble) average of CMIP6 atmospheric

598 models. $\mathbf{g}$ Same as $\mathbf{f}$ but for the best CMIP6 model. $\mathbf{h}$ Same as $\mathbf{g}$ but for the worst

599 CMIP6 model. R, B, C in the panel captions in $\mathbf{d - h}$ denote model's skill scores against

600 the GPCP 1 ddv1.3 observation a. R : The root-mean square error (RMSE, mm day $\left.{ }^{-1}\right)$. B:

601 Bias $\left(\mathrm{mm} \mathrm{day}^{-1}\right) . \mathrm{C}$ : Spatial correlation coefficient (nondimensional). The best and

602 worst models are selected based on RMSE. Values of R, B and C are also plotted in Fig.

6032.

604 
(a) RMSE and Bias

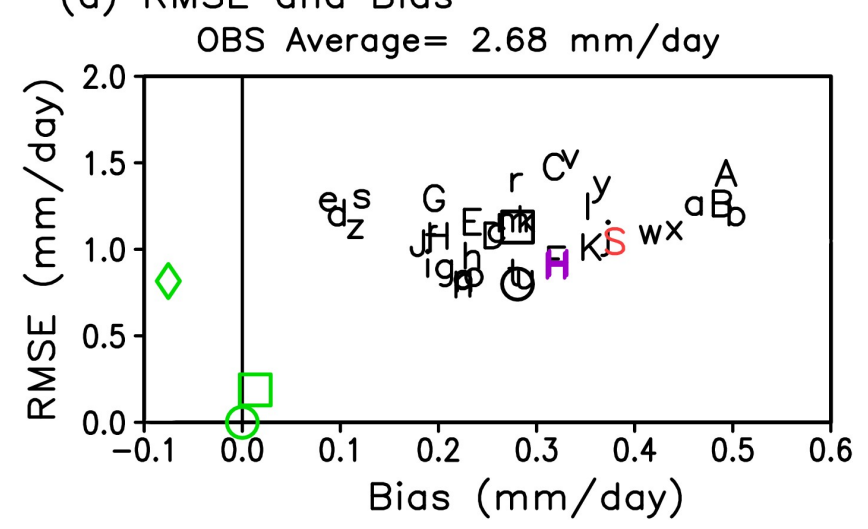

O GPCP 1.0deg

GPCP $2.5 \mathrm{deg}$

$\triangle$ CMAP 2.5deg

S SPD

H HPD

(b) Taylor diagram

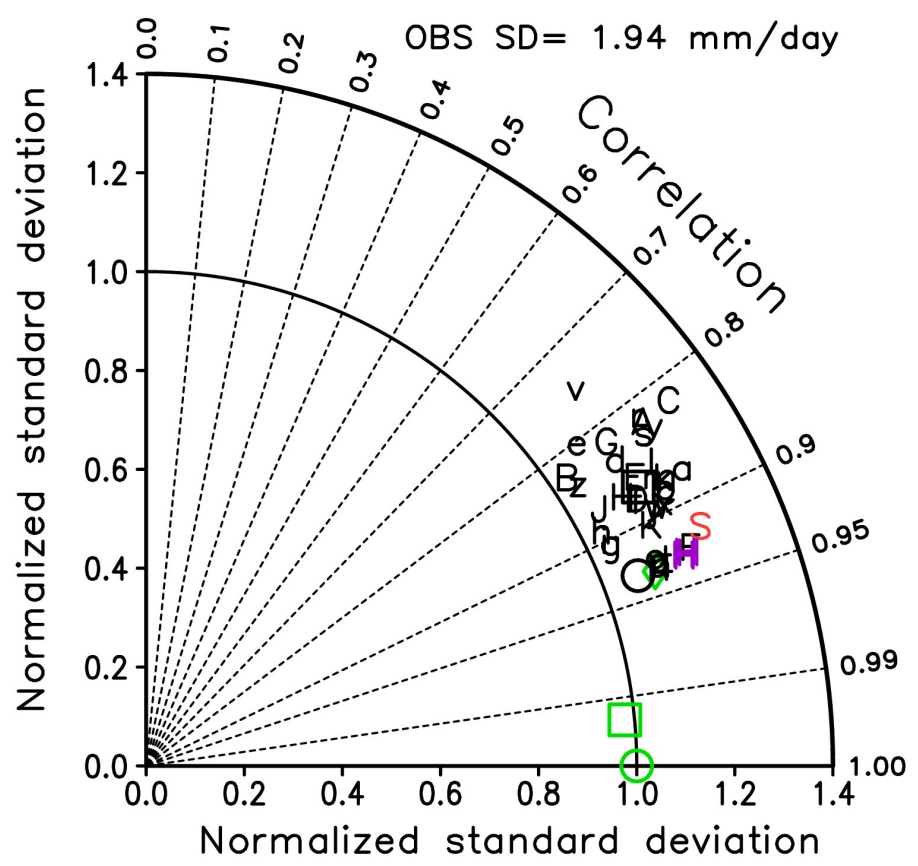

ACCESS-CM2

b ACCESS-ESM1-5

c BCC-CSM2-MR

d BCC-ESM1

e CAMS-CSM1-O

$f$ CanESM5

g CESM2

h CESM2-FV2

i CESM2-WACCM

j CMCC-CM2-SR5

k CNRM-CM6-1

l CNRM-CM6-1-HR

m CNRM-ESM2-1

n EC-Earth3

- EC-Earth3-AerCher

p EC-Earth3-CC

q EC-Earth3-Veg

$r$ FGOALS-f3-L

$s$ FGOALS-g3

$t$ GFDL-CM4

u GFDL-ESM4

$\checkmark$ IITM-ESM

w INM-CM4-8

$\times$ INM-CM5-O

y IPSL-CM6A-LR

z KIOST-ESM

A MIROC6

B MIROC-ES2L

C MPI-ESM-1-2-HAI

D MPI-ESM1-2-HR

E MPI-ESM1-2-LR

F MRI-ESM2-O

$G$ NESM3

H NorCPM1

J NorESM2-LM

$K$ SAMO-UNICON

O MME

a AVM

607 Fig. 2 The skills of simulated annual precipitation over the globe. The GPCP 1dd v1.3

608 data (green circle) are used as reference observation. The target region is similar to

609 Fig. 1. Green square and diamond symbols indicate additional observations (Table 2).

610 Colored letters denote the MRI-AGCM3.2 models. Red S shows the 20-km model.

611 Purple $\mathrm{H}$ shows all four members of the $60-\mathrm{km}$ model simulations. Black letters indicate

612 CMIP6 each models (Table 1). Black circles specify the MME average. Black squares 
613 imply the mean skill scores of entire CMIP6 models (AVM). a The horizonal axis is 614 bias. The vertical axis is RMSE. Units are $\mathrm{mm}$ day $^{-1}$. The domain average of 615 observation is displayed above the panel. b The Taylor diagram (Taylor 2001). The 616 distance relative to the origin corresponds to the standard deviation of a simulated 617 pattern which is standardized based on the observed standard deviation. The angle 618 relative to the vertical axis means the spatial correlation coefficient. The standard 619 deviation of the observation in the domain is displayed above the panel.

620 


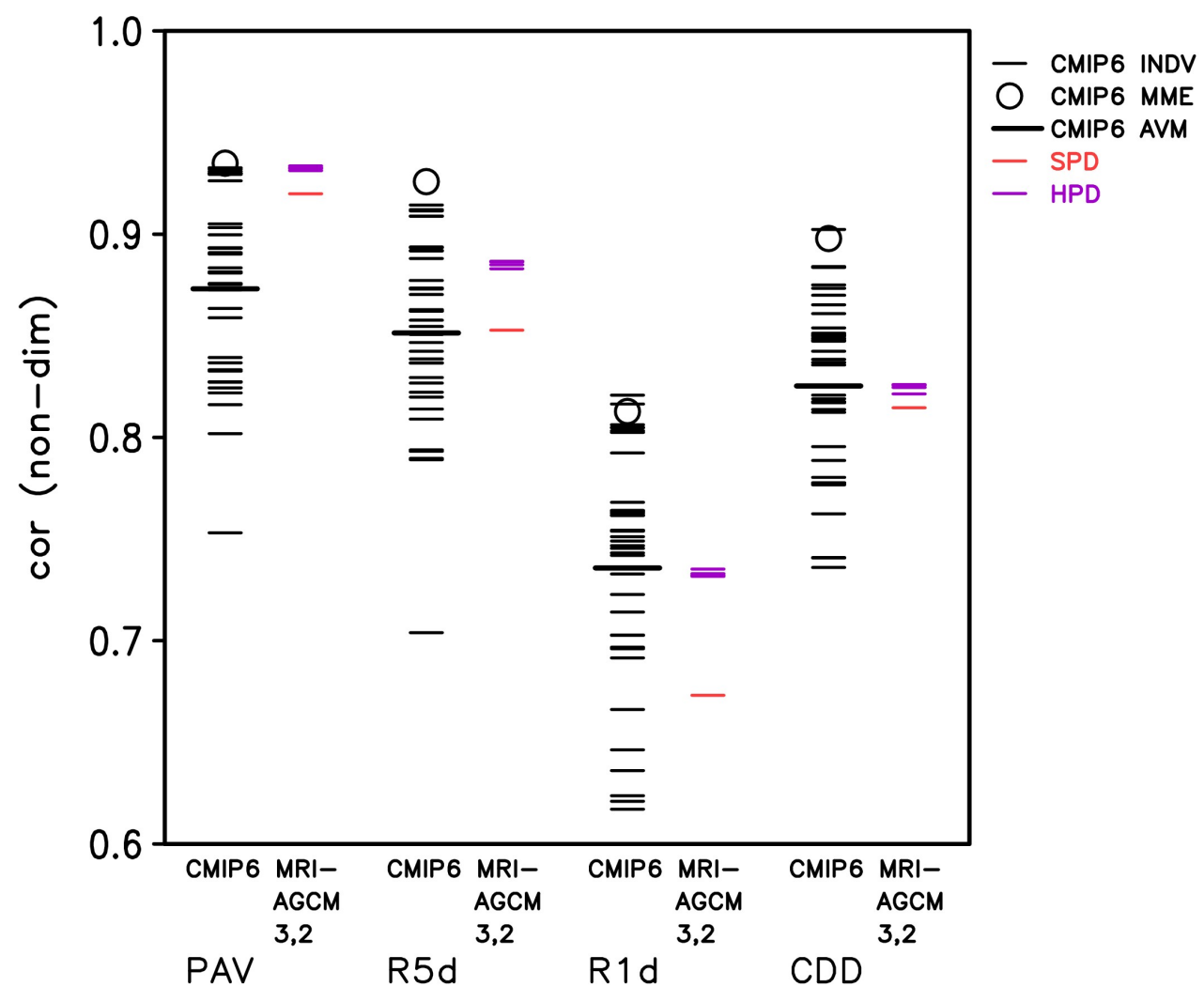

622

623 Fig. 3 Spatial correlation coefficients of model simulations against the observation 624 GPCP 1ddv1.3 as for the global distribution of precipitation indices (Table 3). Red lines 625 display the $20-\mathrm{km}$ model. Purple lines denote the $60-\mathrm{km}$ model. Black bars show the 626 CMIP6 each models. Black circles display the MME average of CMIP6 models. Thick 627 black long lines indicate the AVM of CMIP6 models.

628

629 


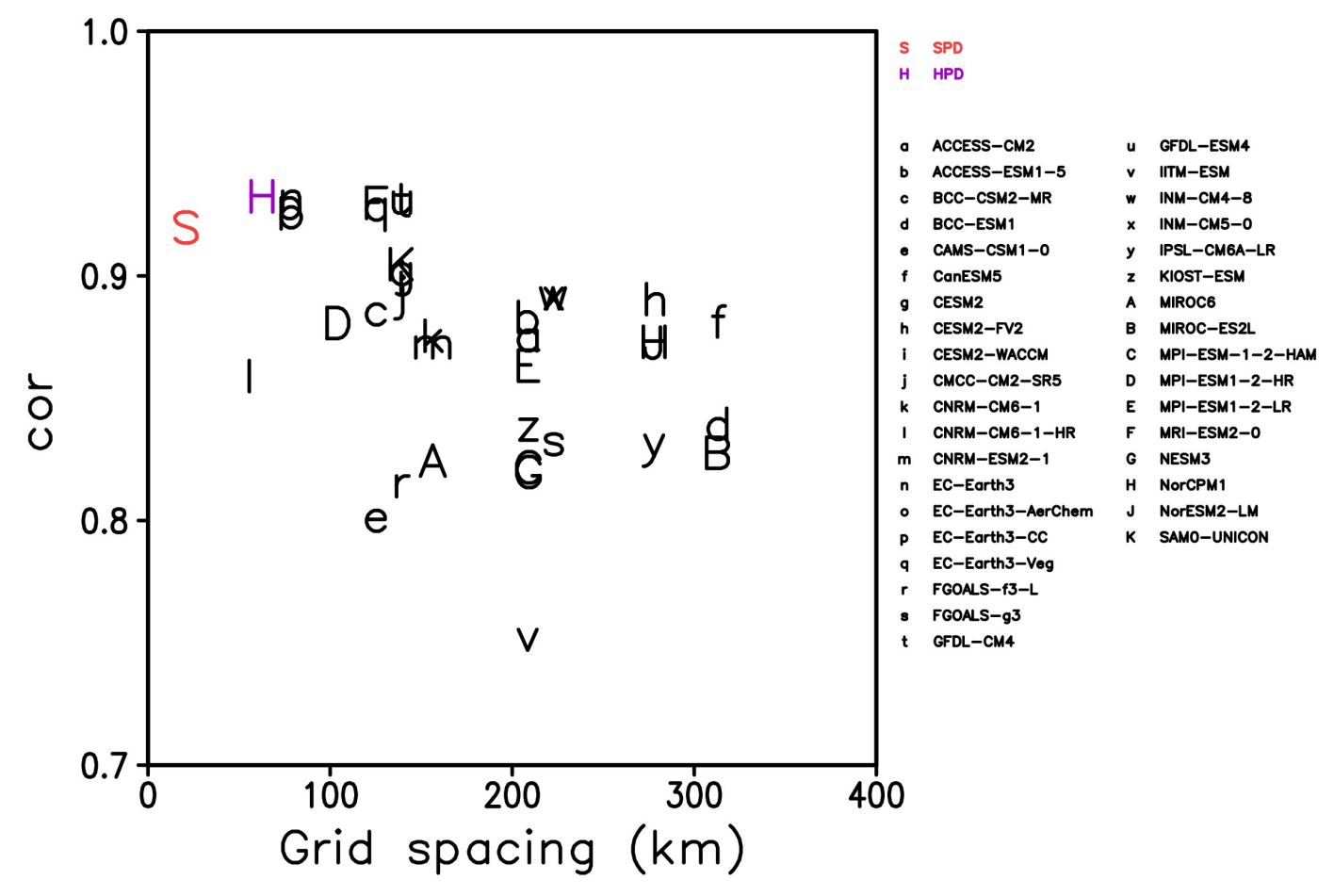

631

632 Fig. 4 Dependence of model skill on the grid spacing at the equator (Table 1, the last 633 column). Red $\mathrm{S}$; the $20-\mathrm{km}$ model, purple $\mathrm{H}$; the $60-\mathrm{km}$ model, black character ;

634 CMIP6 models. The skill measure is the spatial correlation coefficient $\mathrm{C}$ verified against 635 the GPCP 1ddv1.3 observation for the global distribution of annual precipitation PAV.

636 The correlation coefficient between $\mathrm{C}$ and grid spacing is -0.463 which is greater than 637 the $99 \%$ significance level. For the $60-\mathrm{km}$ model, only the first member is chosen out 638 of four ensemble simulation.

639 


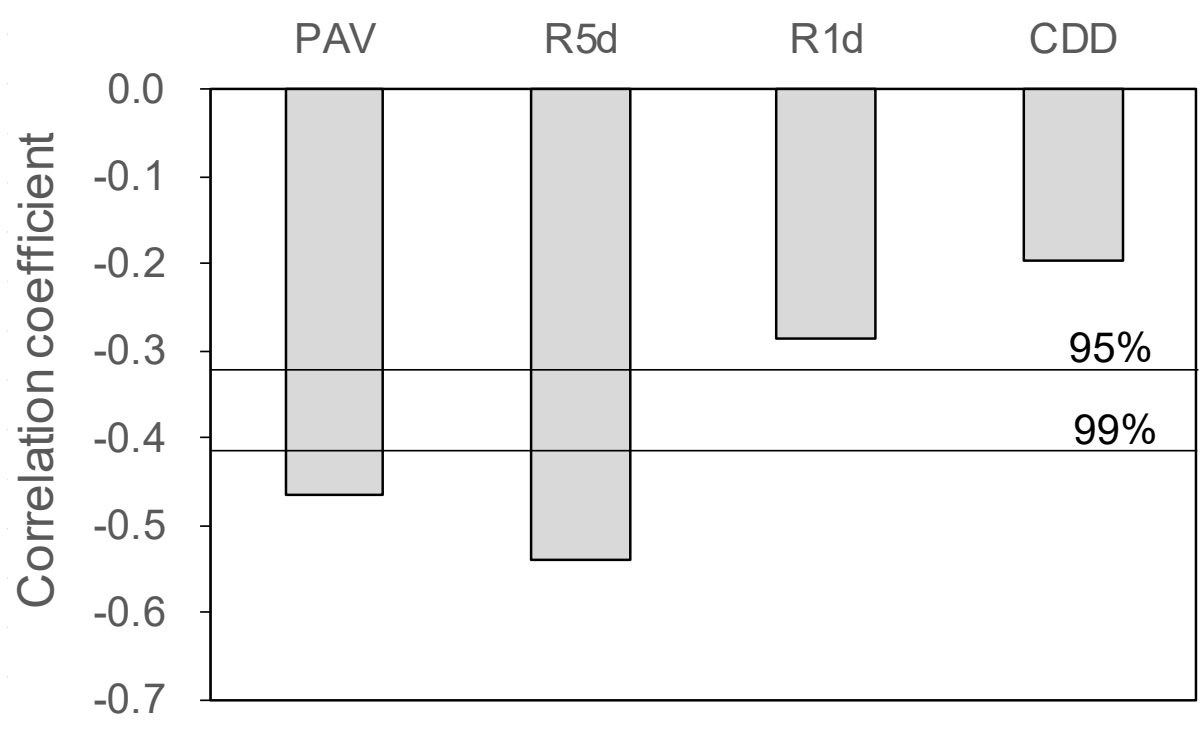

641

642 Fig. 5 Correlation coefficients between the skill and grid spacing based on two

643 MRI-AGCM3.2 models and 36 CMIP6 models (Table 1) for 4 extreme indices (Table 3).

644 For the $60-\mathrm{km}$ model, only the first member is chosen out of four ensemble simulation.

645 The skill measure is the spatial correlation coefficient $\mathrm{C}$ verified against the GPCP

$6461 \mathrm{ddv} 1.3$ observation for the global distribution of extreme indices. Horizontal lines

647 show statistical significance levels. Scatter plot in the case of PAV is displayed in Fig. 4.

648 Larger negative correlation coefficient means that the advantage of higher resolution

649 model over low resolution model is much more evident.

650 
(a) GPCP $1 \mathrm{ddv} 1.3$

1997-2018, 22yr

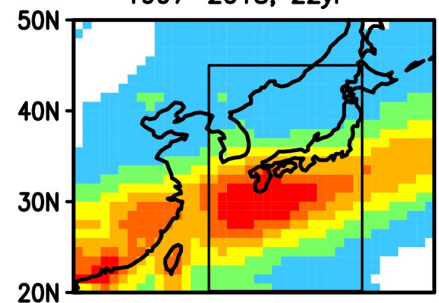

(d) SPD

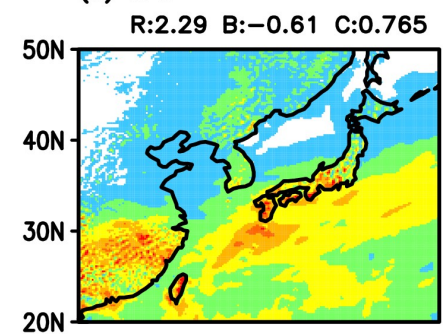

(f) CMIP6 MME

R:2.76 B:-0.69 C:0.646

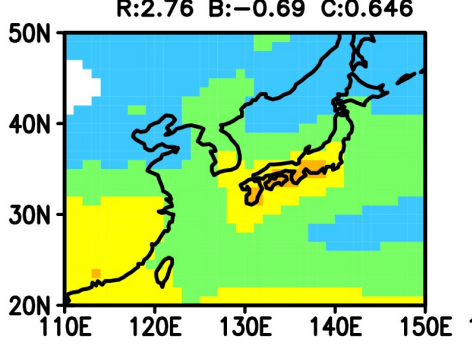

(b) GPCP v2.3

1995-2014, 20yr

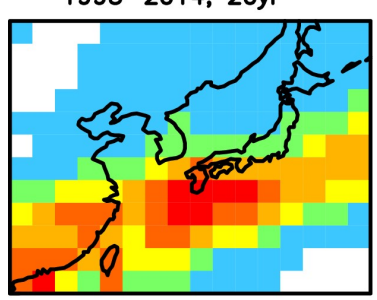

(e) HPD

R:2.17 B:-0.73 C:0.813

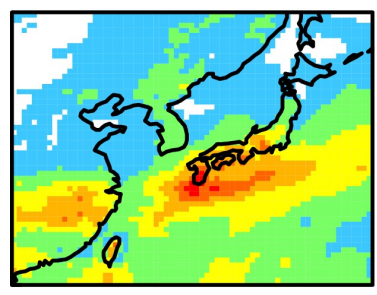

(g) Best CNRM-ESM2-1

R:1.99 B:-0.61 C:0.837

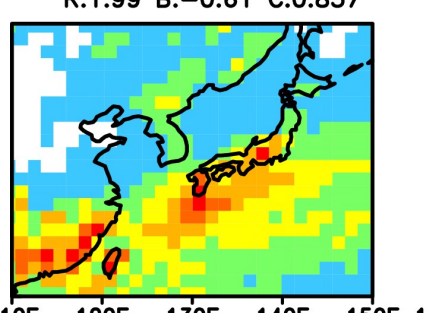

(c) CMAP V1705

1995-2014, 20yr
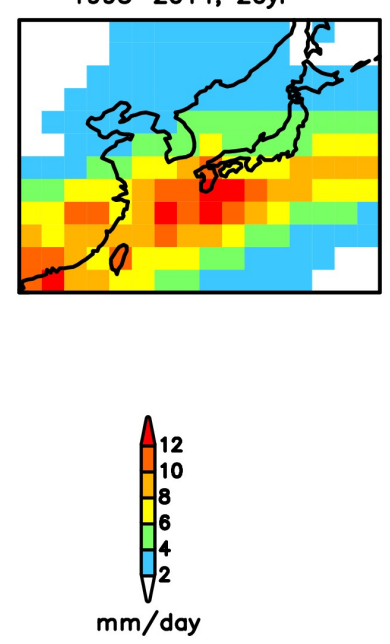

(h) Worst MIROC6

R:4.21 B:0.464 C:0.242

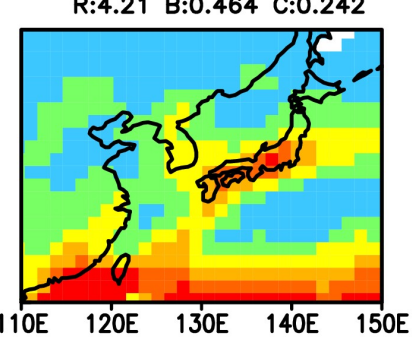

652

653 Fig. 6 Similar to Fig. 1 except for June precipitation. The target region is East Asia

$654\left(110-150^{\circ} \mathrm{E}, 20-50^{\circ} \mathrm{N}\right)$. The black box in a defines the target domain $\left(125-142^{\circ} \mathrm{E}\right.$, $\left.65520-45^{\circ} \mathrm{N}\right)$ selected in Figs. 8-10.

656 
(a) RMSE and Bias

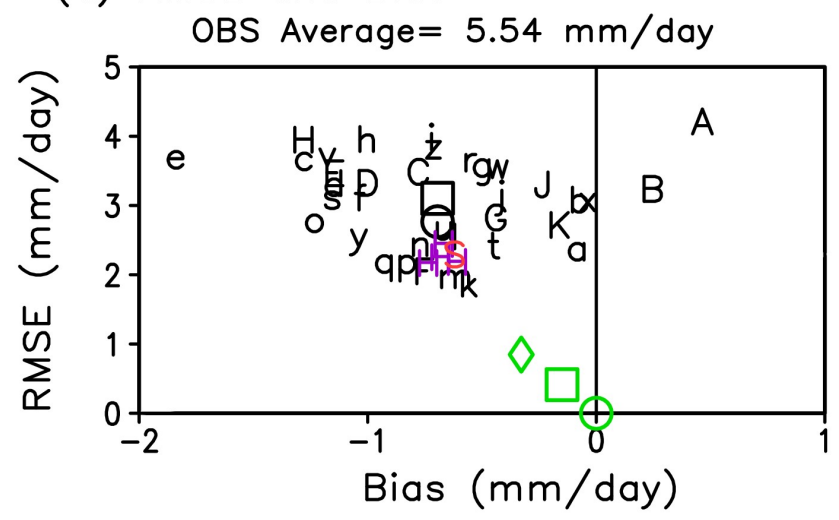

(b) Taylor diagram

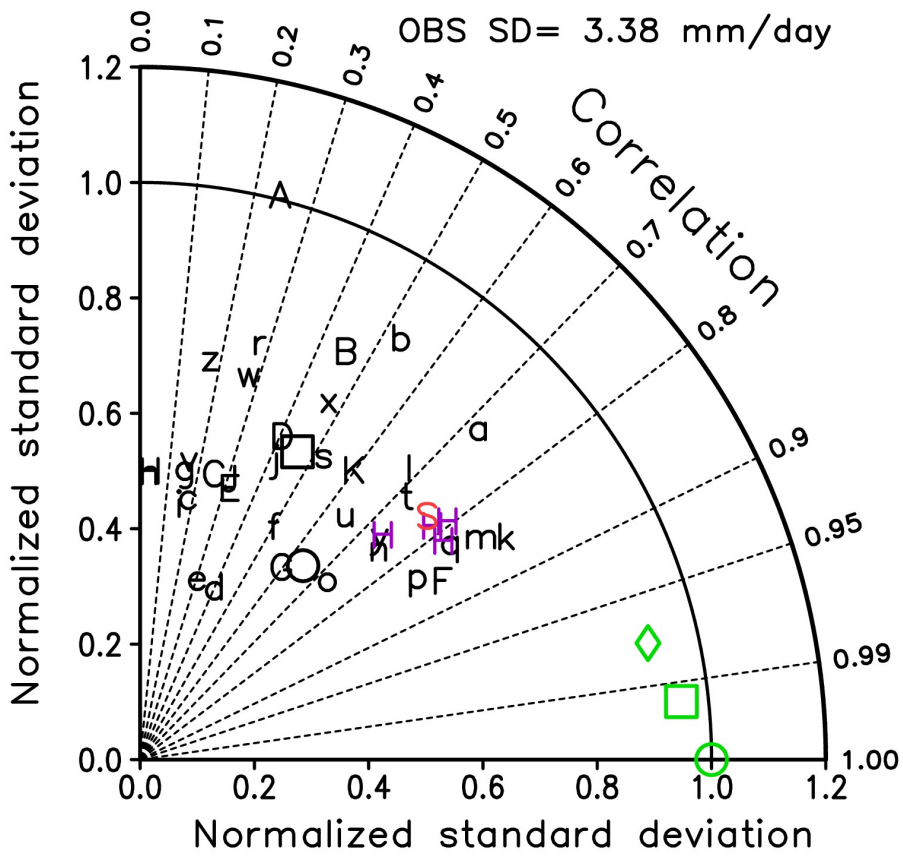

O GPCP 1.0deg

GPCP $2.5 \mathrm{deg}$

$\checkmark$ CMAP 2.5deg

S SPD

H HPD

a ACCESS-CM2

b ACCESS-ESM1-5

c BCC-CSM2-MR

d BCC-ESM1

e CAMS-CSM1-0

f CanEsM5

g CESM2

h CESM2-FV2

i CESM2-WACCM

j CMCC-CM2-SR5

k CNRM-CM6-1

I CNRM-CM6-1-HR

m CNRM-ESM2-1

n EC-Earth3

- EC-Earth3-AerChem

P EC-Earth3-CC

q EC-Earth3-Veg

$r$ FGOALS-f3-L

s FGOALS-g3

t GFDL-CM4

u GFDL-ESM4

$\checkmark$ IITM-ESM

w INM-CM4-8

$\times$ INM-CM5-O

y IPSL-CM6A-LR

z KIOST-ESM

A MIROC6

B MIROC-ES2L

C MPI-ESM-1-2-HAM

D MPI-ESM1-2-HR

E MPI-ESM1-2-LR

F MRI-ESM2-O

G NESM3

H NorCPM1

J NorESM2-LM

K SAMO-UNICON

○ MME

AVM

659 Fig. 7 Similar to Fig. 2 except for June precipitation over East Asia (110-150 E, $\left.660 \quad 20-50^{\circ} \mathrm{N}\right)$

661 


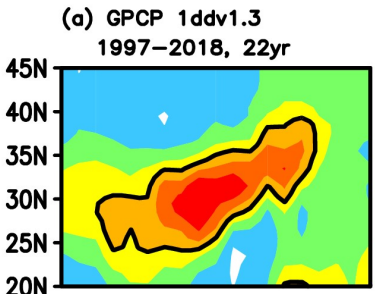

(d) SPD

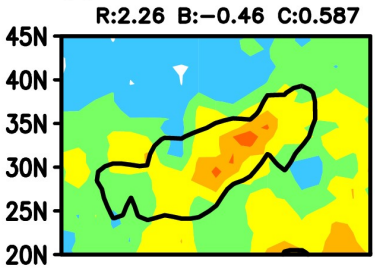

(f) CMIP6 MME

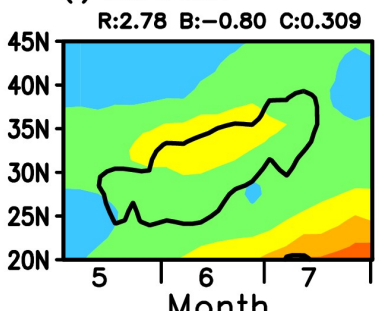

(b) GPCP 2.5 V2.2

1995-2014, 20yr

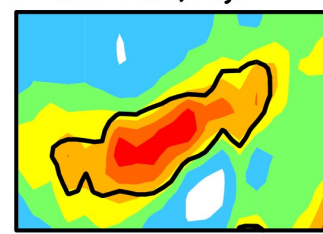

(e) HPD

$R: 2.10$ B: -0.63 C:0.675

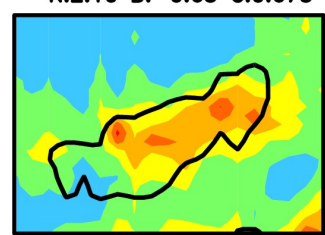

(g) Best CNRM-CM6-1 R:2.13 B:-0.55 C:0.656

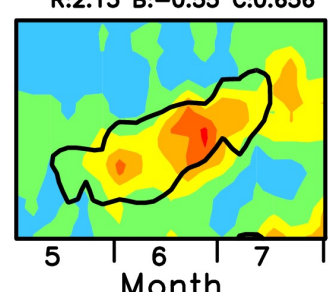

(c) CMAP 2.5 V1701

1995-2014, 20yr

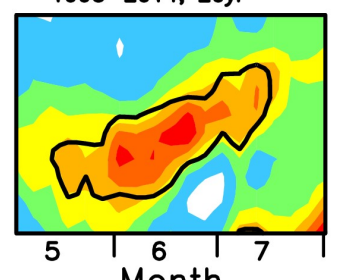

Month

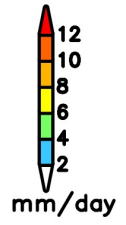

(h) Worst NorESM2-LM R:5.49 B:0.428 C: -0.03

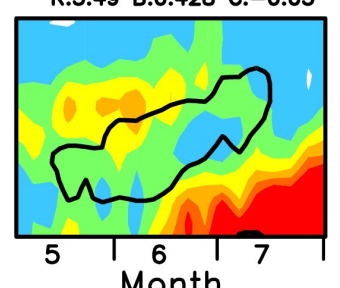

664 Fig. 8 Time evolution of pentad mean precipitation. Observations (Table 2). d-h

665 Model simulations. climatological pentad mean precipitation. Simulated period is 20

666 years from 1995 to 2014 . The target region $\left(125-142^{\circ} \mathrm{E}, 20-45^{\circ} \mathrm{N}\right)$ is displayed by the

667 black box in Fig. 6a. Plotted time span is from pentad 25 (1-5 May) to 43 (30 July - 3

668 August). Unit is mm day ${ }^{-1}$. Similar to Fig. 1, R, B, C in the panel captions in d-h denote

669 model's skill scores against the GPCP $1 \mathrm{ddv} 1.3$ observation a. Contour line of $8 \mathrm{~mm}$

670 day $^{-1}$ defines the Japanese rainy season based on the GPCP 1ddv1.3 observation a. 


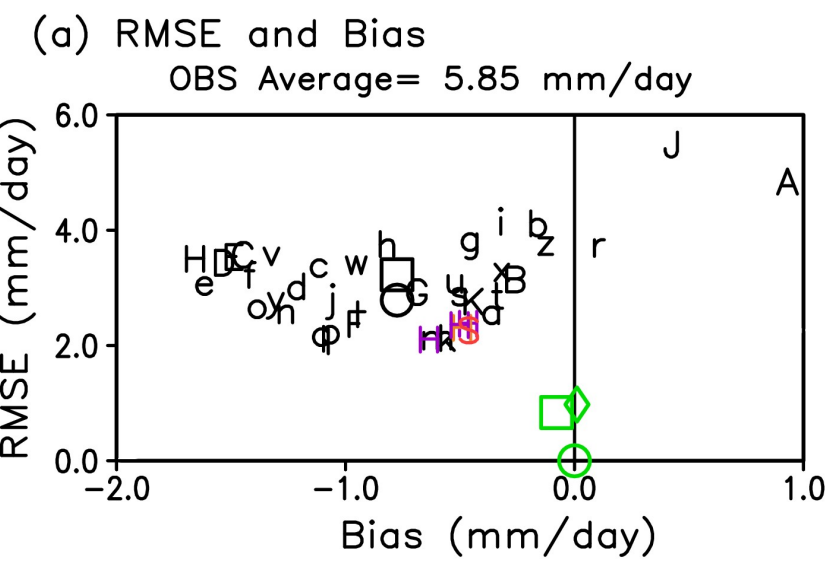

- GPCP 1.0deg

口 GPCP 2.5deg

- CMAP 2.5deg

S SPD

H HPD

a ACCESS-CM2

b ACCESS-ESM1-5

c BCC-CSM2-MR

d BCC-ESM1

- CAMS-CSM1-O

f CanESM5

g CESM2

h CESM2-FV2

i CESM2-WACCM

j CMCC-CM2-SR5

k CNRM-CM6-1

(b) Taylor diagram

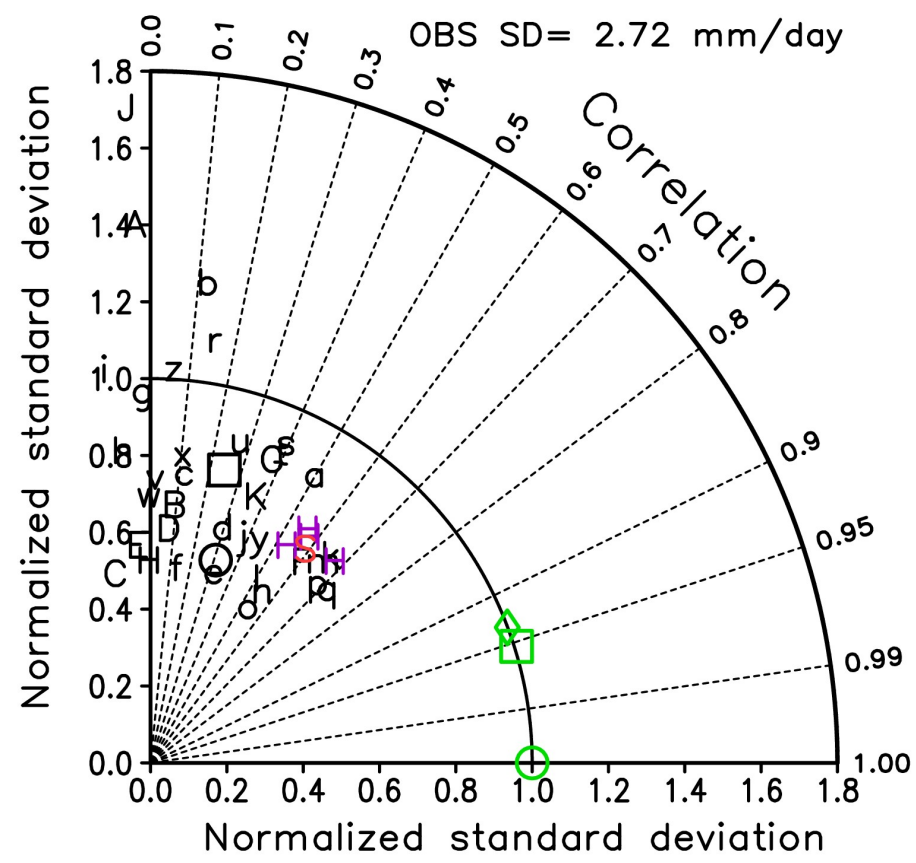

CNRM-CM6-1-HR

m CNRM-ESM2-1

n EC-Earth3

- EC-Earth3-AerChem

p EC-Earth3-CC

q EC-Earth3-Veg

r FGOALS-f3-L

s FGOALS-g3

$t$ GFDL-CM4

u GFDL-ESM4

$\checkmark$ IITM-ESM

w INM-CM4-8

$\times$ INM-CM5-0

y IPSL-CM6A-LR

z KIOST-ESM

A MIROC6

B MIROC-ES2L

C MPI-ESM-1-2-HAM

D MPI-ESM1-2-HR

E MPI-ESM1-2-LR

F MRI-ESM2-0

G NESM3

H NorCPM1

J NorESM2-LM

K SAMO-UNICON

O MME

674 Fig. 9 Same as Fig. 2 but for the seasonal march of the Japanese rainy season (Fig. 8). 


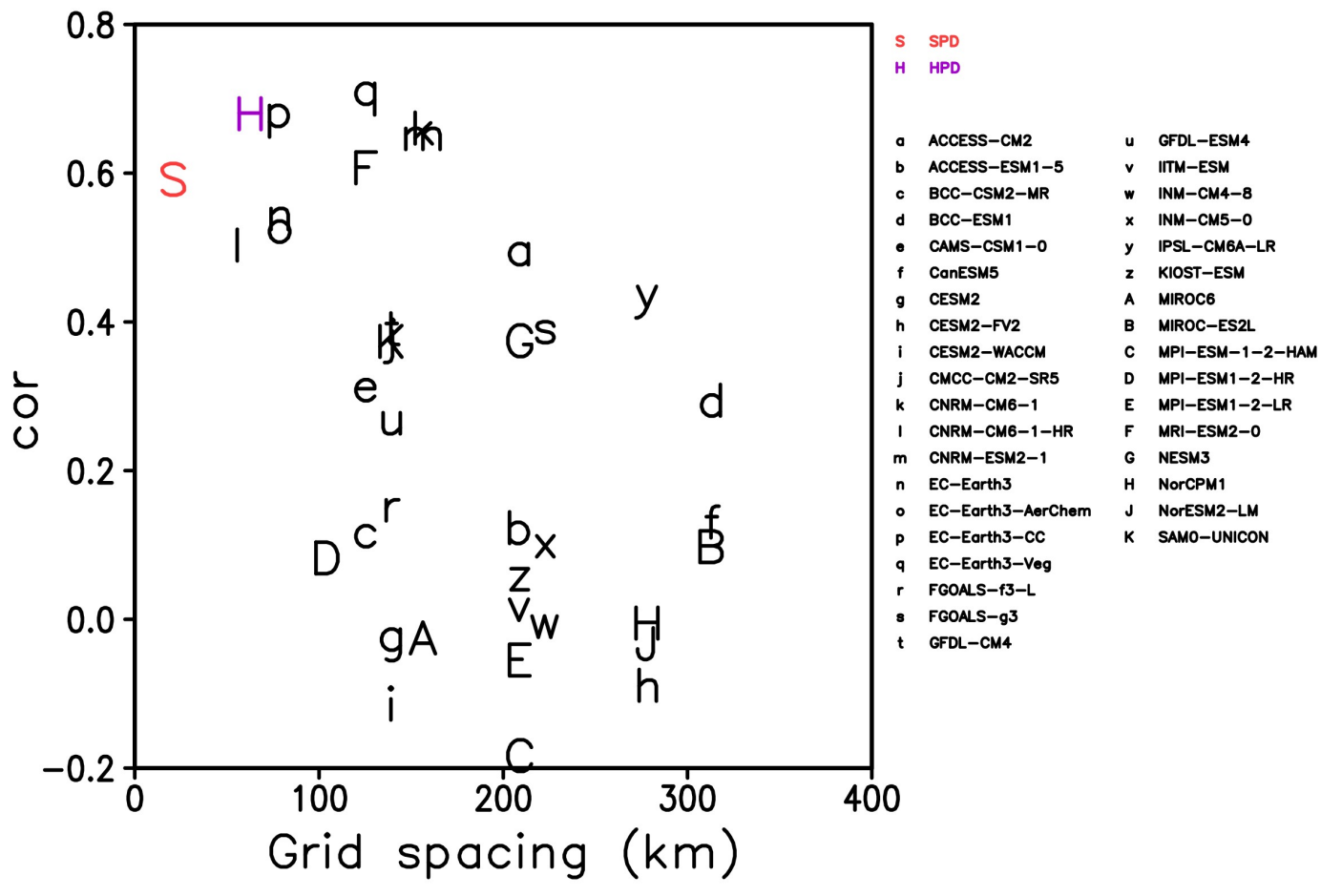

677

678 Fig. 10 Same as Fig. 4 but for the seasonal march of the Japanese rainy season (Figs.

679 8-9). The correlation coefficient between grid spacing and the pattern correlation 680 coefficient for the seasonal march of precipitation is -0.520 , which is greater than the $68199 \%$ significance level.

682 


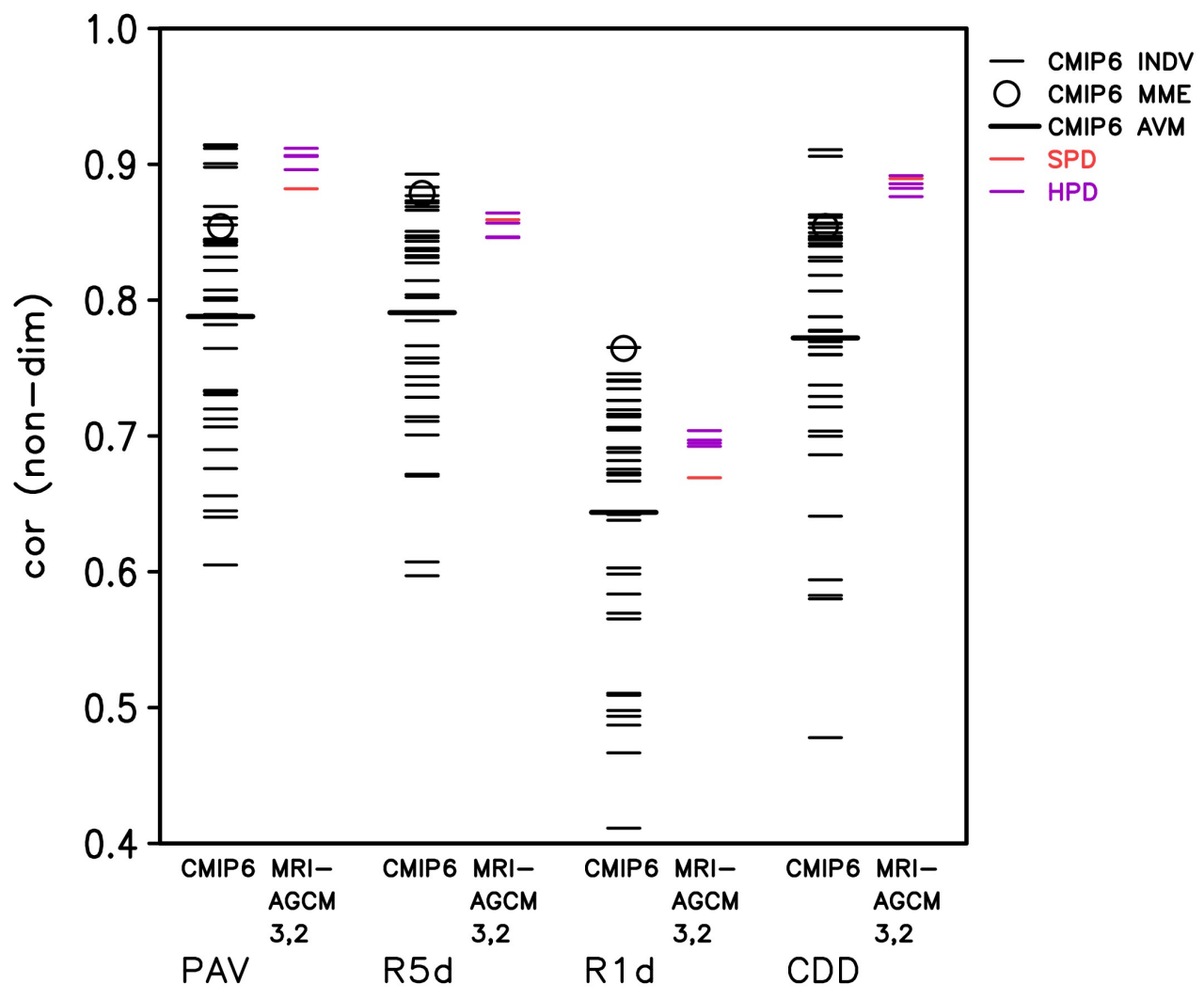

684

685 Fig. 11 Similar to Fig. 3 except for East Asia $\left(110-150^{\circ} \mathrm{E}, 20-50^{\circ} \mathrm{N}\right)$.

686 


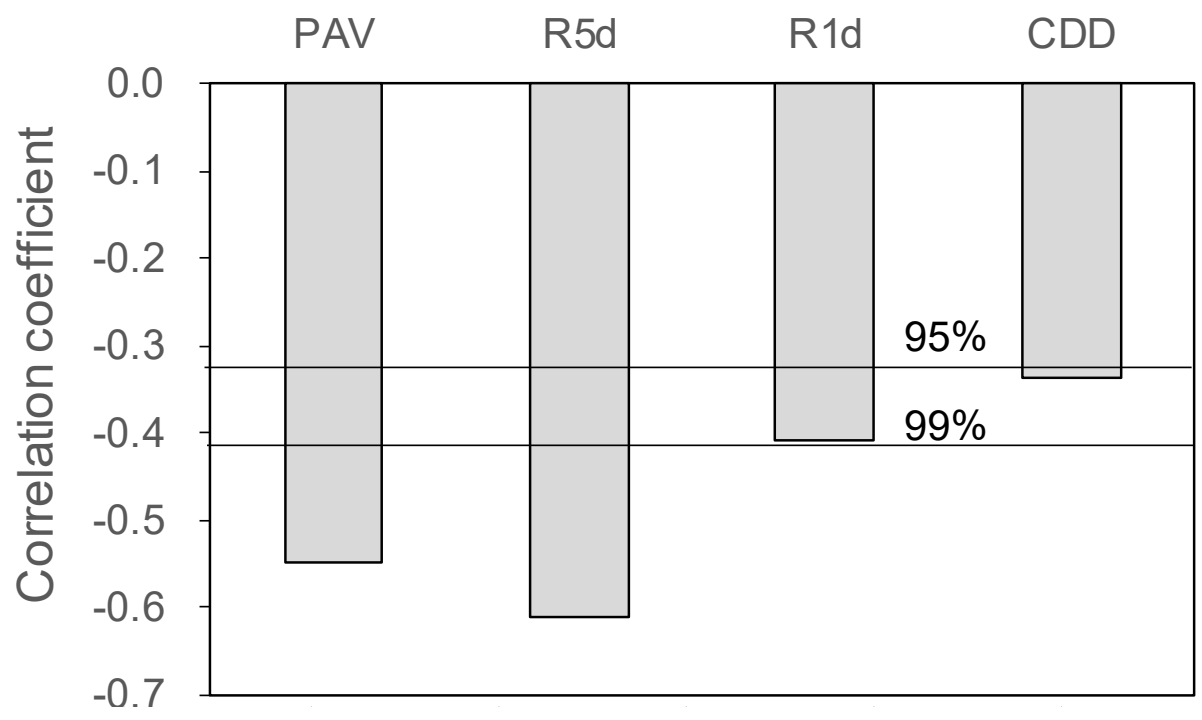

688

689 Fig. 12 Similar to Fig. 5 except for East Asia $\left(110-150^{\circ} \mathrm{E}, 20-50^{\circ} \mathrm{N}\right)$.

690 


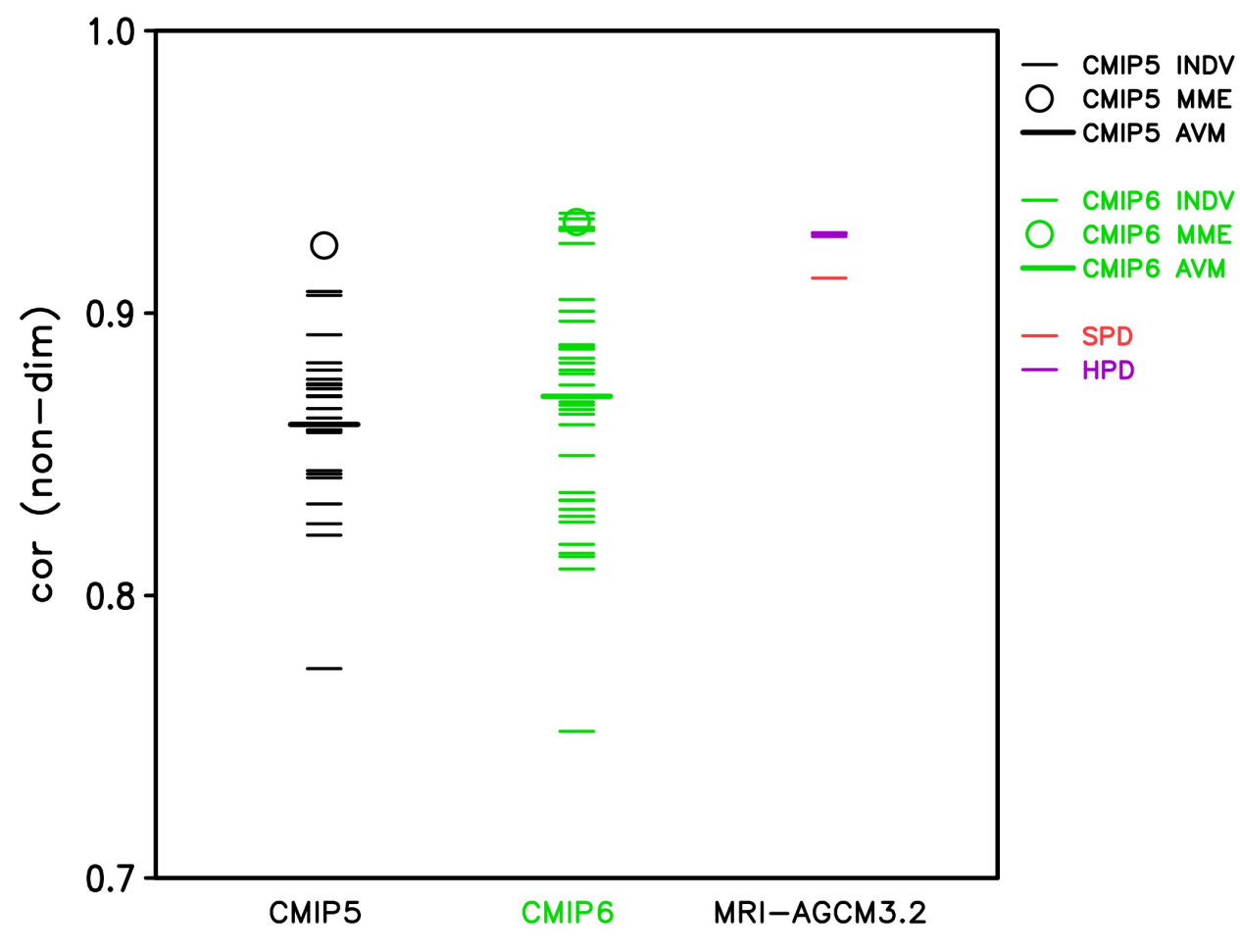

691

692

693 Fig. 13 Comparison among 24 CMIP5 models (black), 36 CMIP6 models (green) and 694 MRI-AGCM3.2 for global annual mean precipitation of the 20 -year period from 1981 to 695 2000. Skill measure is spatial correlation coefficient against the GPCP $1 \mathrm{ddv} 1.3$ 696 observation. For details of CMIP5 models, see Table 5 in Kusunoki and Mizuta (2021). 697 


\section{Supplementary material}

699

700 Kusunoki, S., T. Nakaegawa, and R. Mizuta, 2022: Does the atmospheric global model MRI-AGCM3.2 perform better than CMIP6 atmospheric models in simulating precipitation? Climate Dynamics, doi:10.1007/s00382-???

703 
(a) GPCP $1 \mathrm{ddv} 1.3$

1997-2018, 22yr
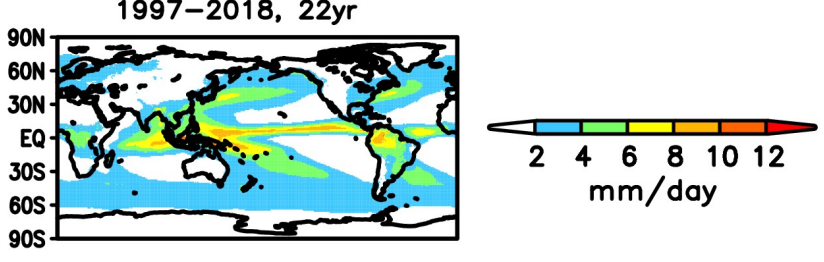

(b) SPD

R:1.04 B:0.37 C:0.918

(c) HPD

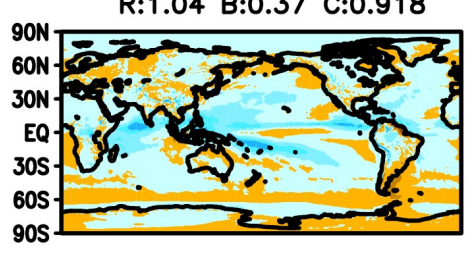

R:0.91 B:0.32 C:0.931

(d) CMIP6 MME

$R: 0.79$ B:0.28 C:0.933
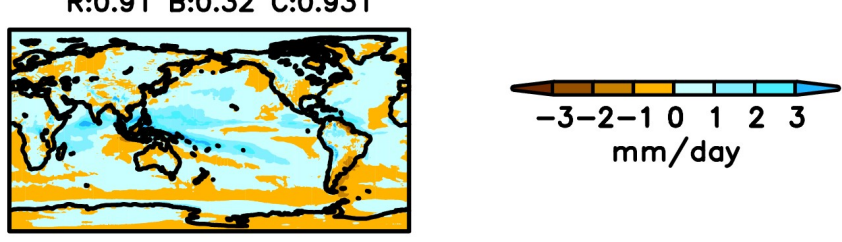

(e) Best EC-Earth3 R:0.83 B:0.22 C:0.931

(f) Worst IITM-ESM
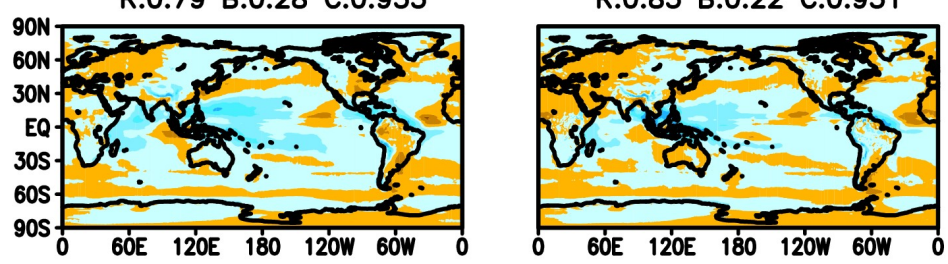

R:1.54 B:0.33 C:0.752

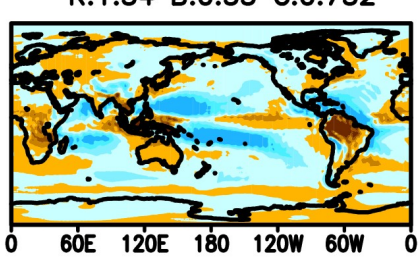

705

706 Fig. S1 The biases of annual precipitation PAV (mm day $\left.{ }^{-1}\right)$. a Reference observation

707 GPCP 1ddv1.3 used for verification. b Bias of SPD averaged for 1995-2014 (20 years).

708 c Similar to b except for HPD. d Similar to b except for the MME (multi-model

709 ensemble) average of CMIP6 atmospheric models. e Similar to d except for the best

710 CMIP6 model. f Similar to d except for the worst CMIP6 model. R, B, C in the panel

711 captions in b-f denote model's skill scores against the GPCP 1 ddv1.3 observation $\mathbf{a}$. R :

712 The root-mean square error (RMSE), B: Bias, C : Spatial correlation coefficient. The

713 best and worst models are selected based on RMSE.

714

715 
(a) GPCP $1 d d v 1.3$

1997-2018, 22yr

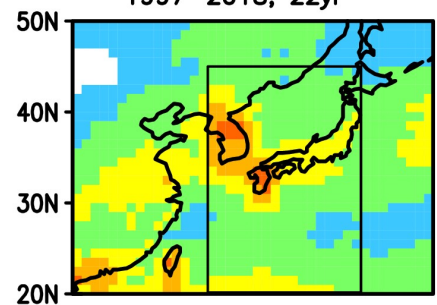

(d) SPD

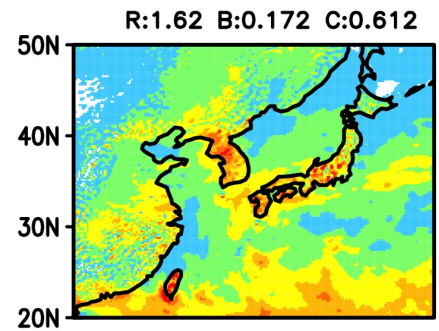

(f) CMIPG MME

R:2.10 B:0.023 C:0.309

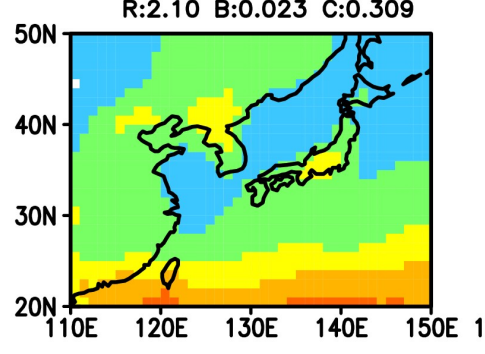

(b) GPCP v2.3

1995-2014, 20yr

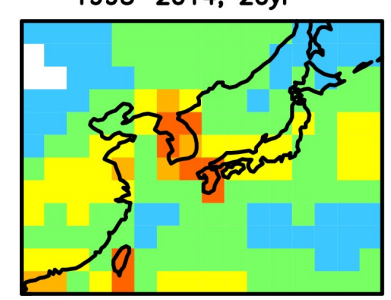

(e) HPD

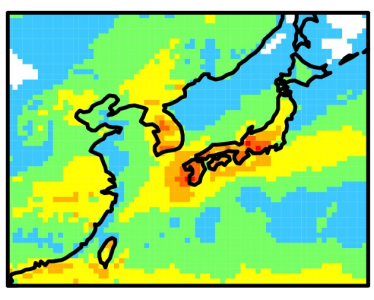

(g) Best CNRM-ESM2-1 R:1.47 B:-0.40 C:0.669 (c) CMAP v1705

1995-2014, 20yr
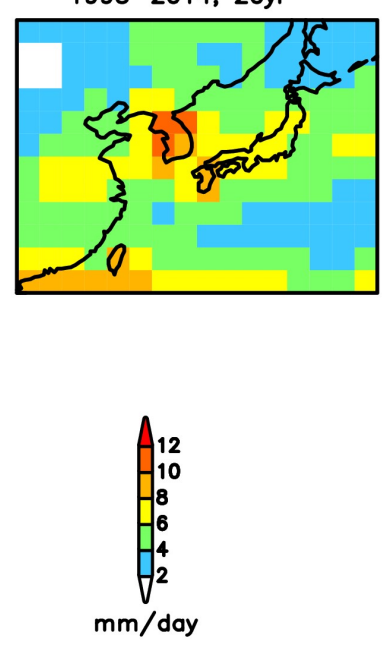

(h) Worst NorESM2-LM

R:5.83 B:1.805 C:0.065

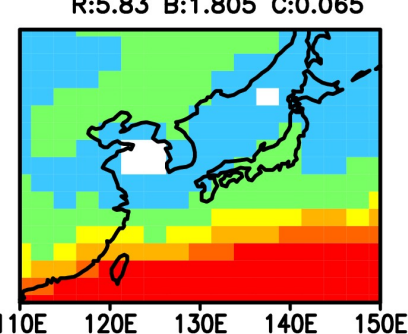

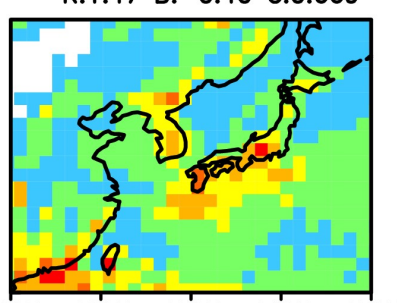

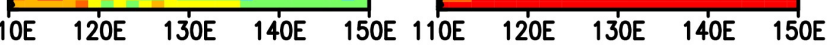

718 Fig. S2 Same as Fig. 6 but for July.

719 
(a) RMSE and Bias

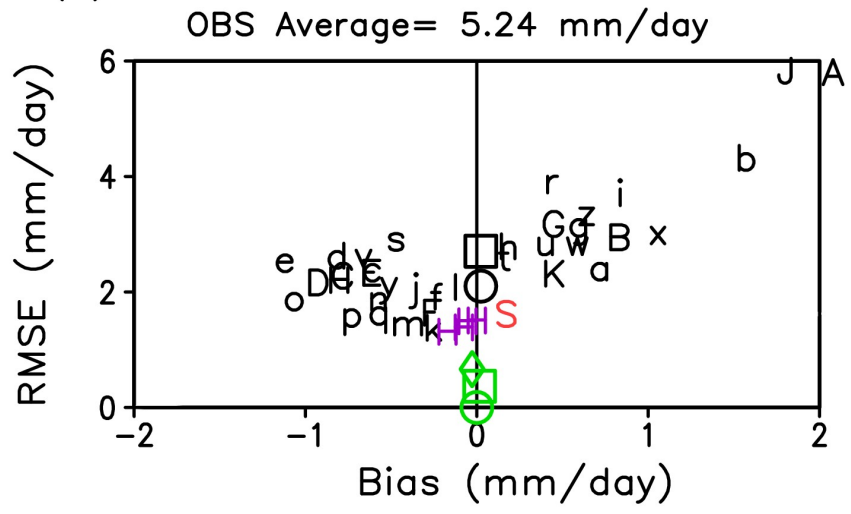

(b) Taylor diagram

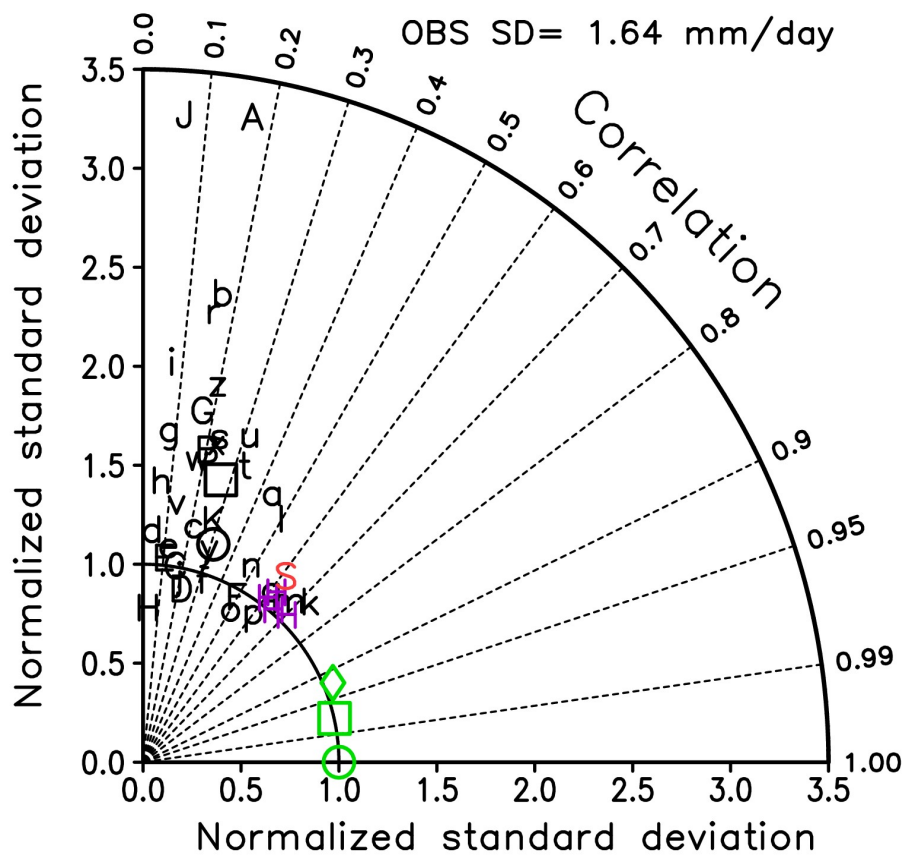

- GPCP 1.0deg

a GPCP $2.5 \mathrm{deg}$

$\checkmark$ CMAP $2.5 \mathrm{deg}$

S SPD

H HPD

a ACCESS-CM2

b ACCESS-ESM1-5

c BCC-CSM2-MR

d BCC-ESM1

e CAMS-CSM1-0

f CanEsM5

g CESM2

h CESM2-FV2

i CESM2-WACCM

j CMCC-CM2-SR5

k CNRM-CM6-1

I CNRM-CM6-1-HR

$m$ CNRM-ESM2-1

$n$ EC-Earth3

- EC-Earth3-AerChem

p EC-Earth3-CC

q EC-Earth3-Veg

$r$ FGOALS-f3-L

s FGOALS $-\mathrm{g} 3$

t GFDL-CM4

u GFDL-ESM4

$\checkmark$ IITM-ESM

w INM-CM4-8

$\times$ INM-CM5-0

y IPSL-CM6A-LR

z KIOST-ESM

A MIROC6

B MIROC-ES2L

C MPI-ESM-1-2-HAM

D MPI-ESM1-2-HR

E MPI-ESM1-2-LR

F MRI-ESM2-O

G NESM3

H NorCPM1

$J$ NorESM2-LM

K SAMO-UNICON

○ MME

口 AVM

723 Fig. S3 Same as Fig. 7 but for July. 


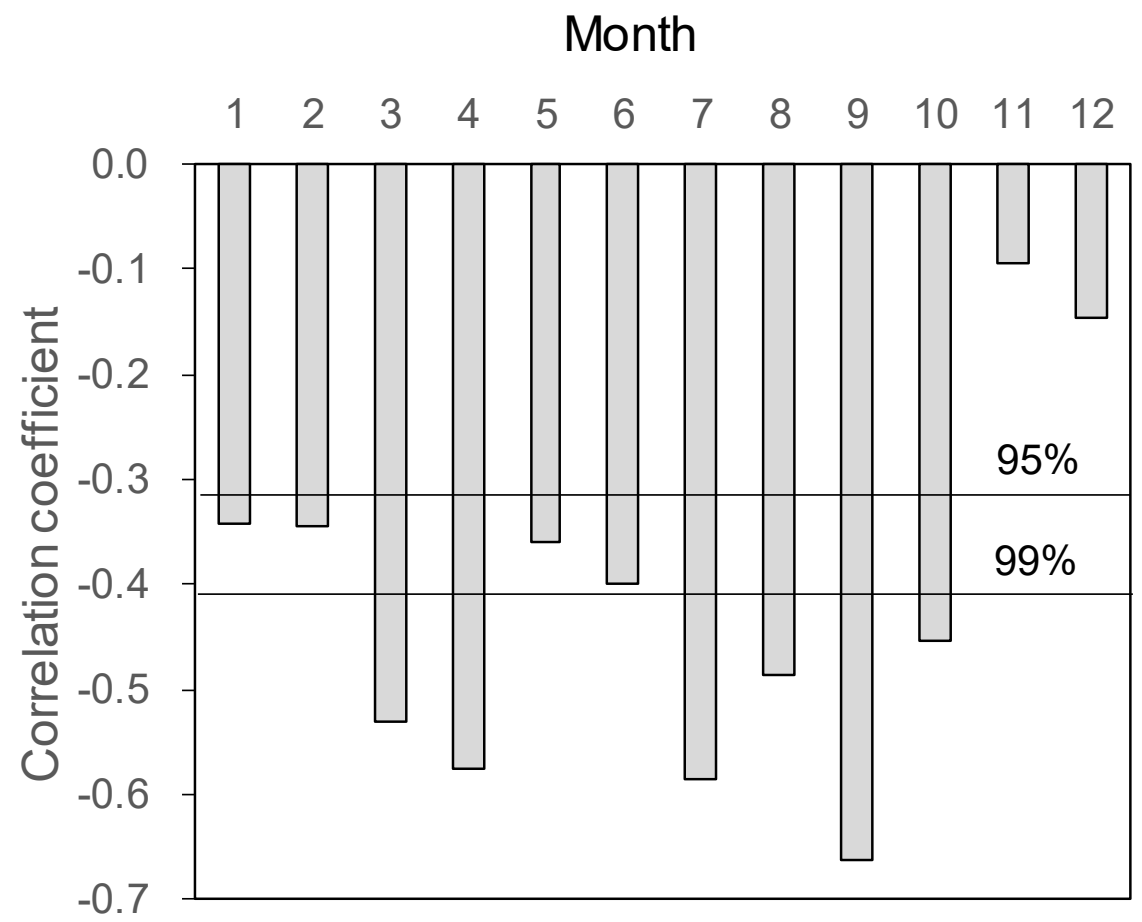

727

728 Fig. S4 Same as Fig. 5 but for monthly precipitation in East Asia region $\left(110-150^{\circ} \mathrm{E}\right.$, $\left.729 \quad 20-50^{\circ} \mathrm{N}\right)$.

730 


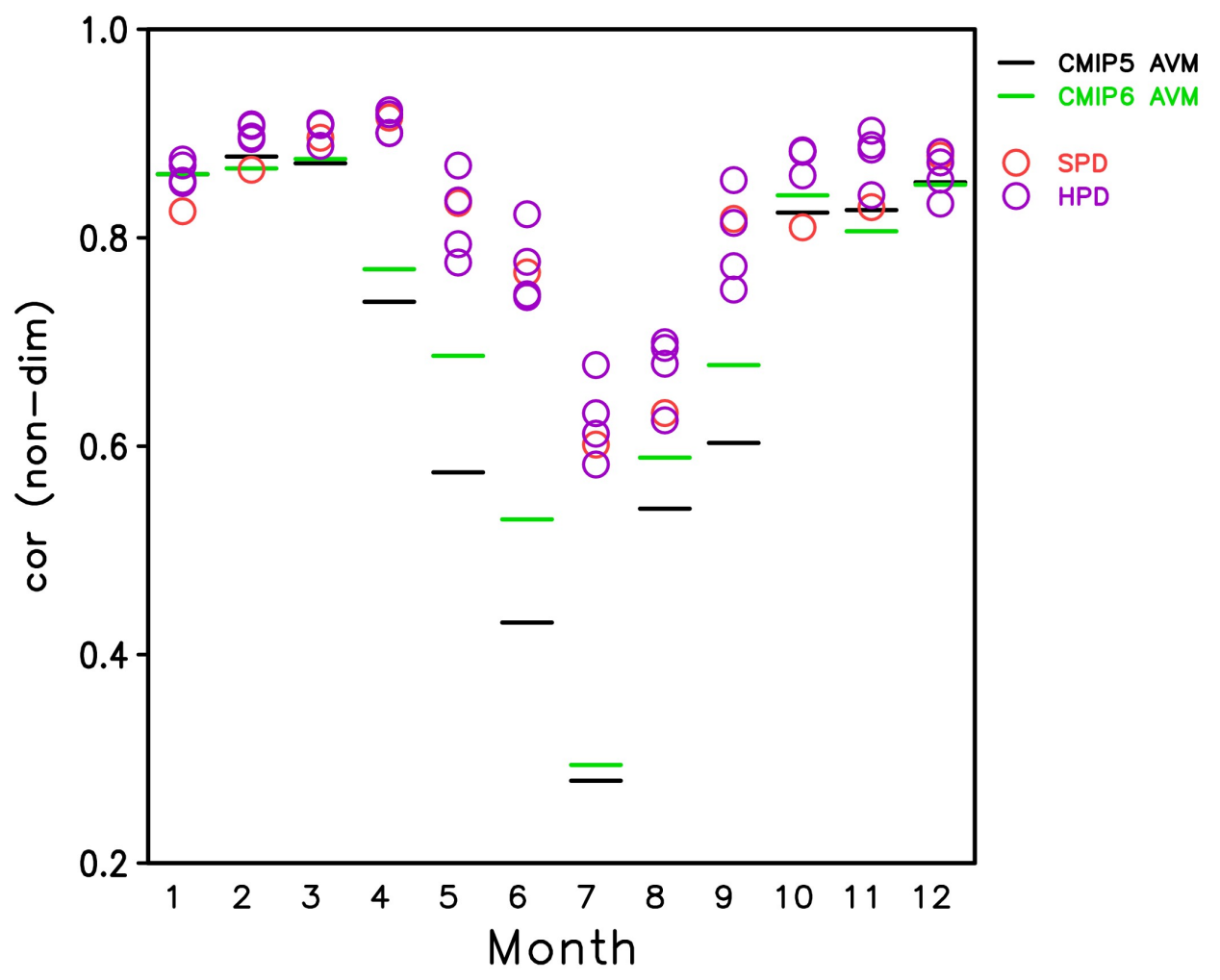

731

732

733 Fig. S5 Comparison among CMIP5 AVM (black line), CMIP6 AVM (green line),

734 SPD (red circle) and four HPDs (purple circles). Skill measure is spatial correlation

735 coefficient for monthly precipitation in East Asia $\left(110-150^{\circ} \mathrm{E}, 20-50^{\circ} \mathrm{N}\right)$. Target period

736 is 20 years from 1981 to 2000.

737 


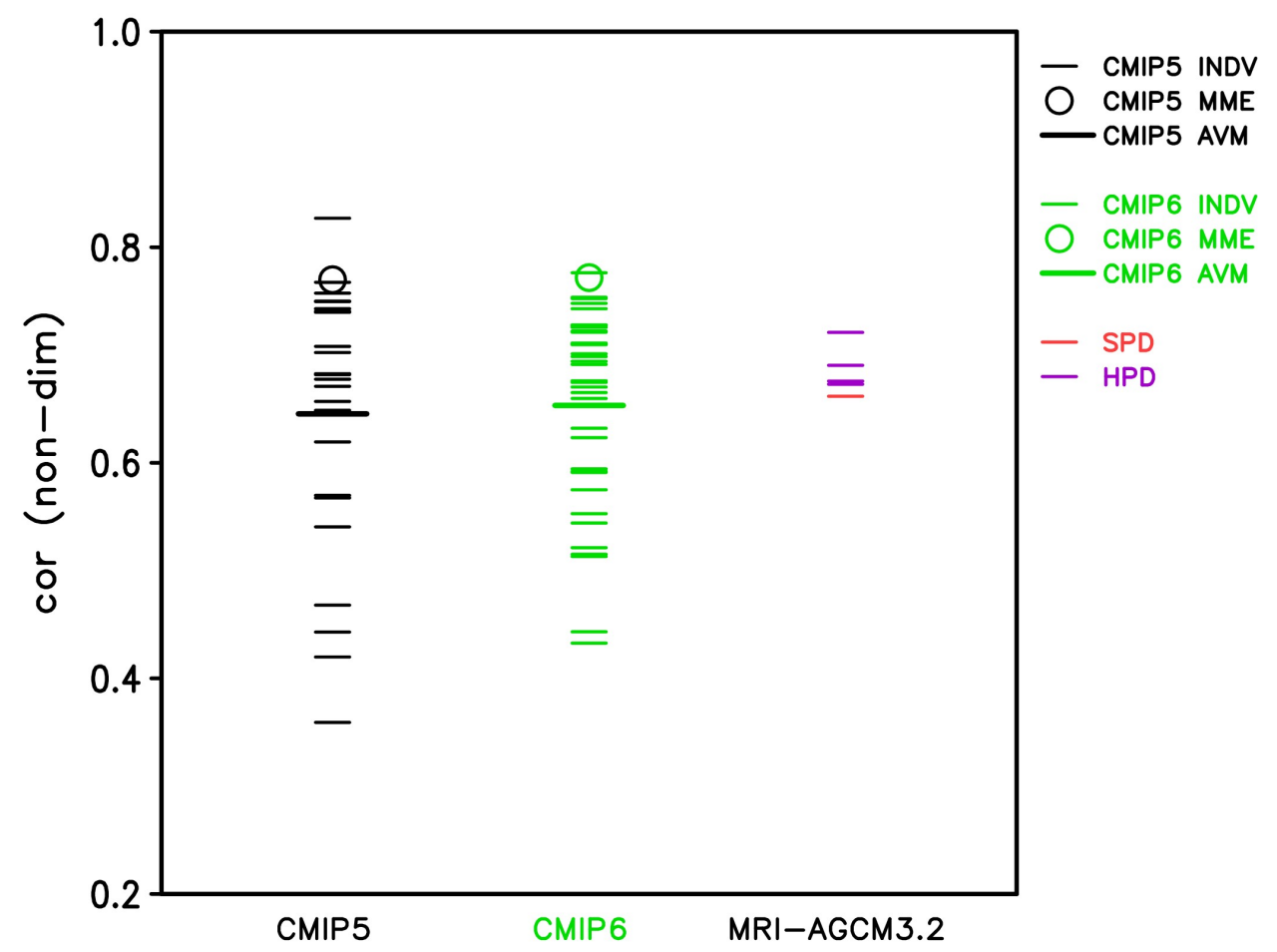

739

740 Fig. S6 Comparison among individual CMIP5 models (black line), individual CMIP6

741 models (green lines), SPD (red line) and four HPDs (purple line). Skill measure is

742 spatial correlation coefficient for R1d in East Asia $\left(110-150^{\circ} \mathrm{E}, 20-50^{\circ} \mathrm{N}\right)$. Thick long

743 lines show AVM. Circles show MME average. Target period is 20 years from 1981 to 7442000. 


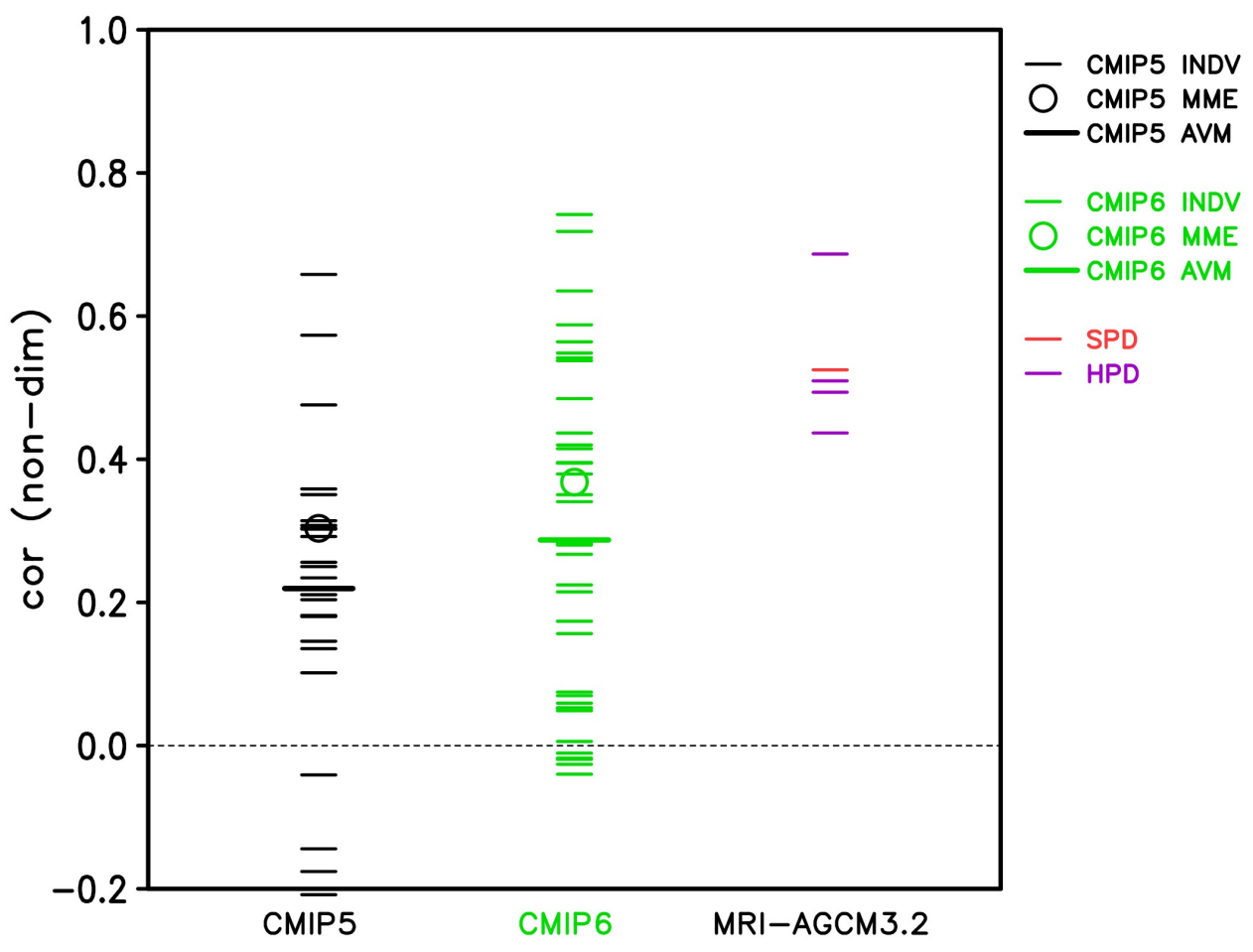

747

748 Fig. S7 Same as Fig. S6 but for the seasonal march of the Japanese rainy season 'Baiu'

749 based on the time evolution of pentad precipitation averaged over the longitude $750 \quad 125-142^{\circ} \mathrm{E}$. Target pentad period and latitude is the same as Fig. 8. 